\title{
$\gamma$-Secretase-Regulated Signaling Mechanisms: Notch and Amyloid Precursor Protein
}

\author{
Kohzo Nakayama ${ }^{1}$, Hisashi Nagase ${ }^{2}$, \\ Chang-Sung Koh ${ }^{3}$ and Takeshi Ohkawara ${ }^{1}$ \\ ${ }^{1}$ Department of Anatomy, \\ ${ }^{2}$ Department of Immunology and Infectious Diseases, \\ Shinshu University, School of Medicine, \\ ${ }^{3}$ Department of Biomedical Sciences, \\ Shinshu University, School of Health Sciences, Matsumoto \\ Japan
}

\section{Introduction}

In Drosophila, Notch mutations lost a lateral signaling ability and produced a neurogenic phenotype, where cells destined to become epidermis switch fate and give rise to neural tissue (Artavanis-Tsakonas et al. 1995; Lewis 1998). Therefore, when Notch signaling was disrupted, too many neurons were generated. Notch attracted further interest because sel12, which appears to facilitate the reception of signaling mediated by lin-12 (C. elegans Notch), was identified by screening for a suppressor of lin-12 gain-of-function mutation (Levitan and Greenwald 1995). Since sel-12 is thought to be a counterpart of human presenilin (PS), which is a catalytic component of $\gamma$-secretase and has been implicated in Alzheimer's disease (AD), it was thought that the Notch signaling pathway might have a close relation with AD. Thus, many scientists have investigated the relationship between Notch signaling and AD. As we focused below, it has become clear that the Notch signaling pathway is controlled by $\gamma$-secretase-mediated proteolysis.

Both Notch receptors and their ligands are evolutionally conserved single transmembranespanning proteins (type 1 transmembrane protein; amino terminus is extracellular and carboxyl terminus is cytoplasmic.) that control the fates of numerous cells in both invertebrates and vertebrates (Artavanis-Tsakonas et al. 1995; Artavanis-Tsakonas et al. 1999; Justice and Jan 2002). For example, Delta, a major Notch ligand, expressing cells inhibit the neural determination of neighboring Notch-expressing neural stem cells (NSCs) during neurogenesis (Nakayama et al. 2008a). In addition, it is well known that isoforms of Notch mediate somitogenesis, differentiation of lymphoid cells as well as differentiation of NSCs, and that dysregulation of Notch signaling causes developmental defects or cancer in mammals (Bolos et al. 2007).

The molecular mechanism of Notch signaling is quite unique in that it is controlled by proteolytic cleavage reactions (Artavanis-Tsakonas et al. 1999; Justice and Jan 2002). In the canonical Notch signaling pathway, ligands bind to the extracellular domain of Notch on 
neighboring cells, and trigger sequential proteolytic cleavage. Finally, the intracellular domain (ICD) of Notch (NICD) is released from the cell membrane by $\gamma$-secretase and translocates to the nucleus to modulate gene expression through binding to transcription factors. Therefore, $\gamma$-secretase plays a central regulatory role in Notch signaling. First, we give a detailed interpretation of Notch itself and Notch signaling as well as its role in differentiation of NSCs.

The Notch signaling pathway has long been believed to be mono-directional because ligands for Notch were generally considered unable to transmit signals into the cells expressing them (Fitzgerald and Greenwald 1995; Henderson et al. 1997). However, several groups have shown that Delta is cleaved sequentially by proteases, probably including ADAM and $\gamma$-secretase (Ikeuchi and Sisodia 2003; LaVoie and Selkoe 2003; Six et al. 2003), and ICD of Delta is released from the cell membrane and translocates to the nucleus (LaVoie and Selkoe 2003; Six et al. 2003). We have also shown that ICD of mouse Delta binds to Smads, which are transcription factors for TGF- $\beta$ / Activin signaling pathway, and enhances transcription of specific genes required for neuronal differentiation (Hiratochi et al. 2007). These results suggest that Delta also has a signaling mechanism similar to Notch signaling. Thus, we also review this issue that the Notch-Delta signaling pathway is bi-directional and similar mechanisms regulated by $\gamma$-secretase are involved in both directions of the NotchDelta signaling pathway in developing NSCs.

$\gamma$-Secretase was first identified as a protease that cleaves amyloid precursor protein (APP) within the transmembrane (TM) domain and produces $\mathrm{A} \beta$ peptides (Haass and Selkoe 1993), which are thought to be pathogenic in AD (Hardy 1997; Selkoe 2001). However, the physiological functions of $\gamma$-secretase have not been clarified (Kopan and Ilagan 2004; Selkoe and Wolfe 2007). Recently, it was demonstrated that more than 50 type 1 transmembrane proteins, including APP, Notch and Delta, are substrates for $\gamma$-secretase (McCarthy et al. 2009) and their ICDs are also released from the cell membrane, similar to Notch. These observations that the common enzyme, $\gamma$-secretase, modulates proteolysis and the turnover of putative signaling molecules have led to the attractive hypothesis that mechanisms similar to the Notch signaling pathway may contribute widely to $\gamma$-secretase-regulated signaling pathways (Koo and Kopan 2004; Nakayama et al. 2008a; Nakayama et al. 2011).

Interestingly, it has also been reported that ICD of APP (AICD), which is released from the cell membrane by $\gamma$-secretase, translocates to the nucleus (Cupers et al. 2001; Gao and Pimplikar 2001; Kimberly et al. 2001) and may function as a transcriptional regulator (Cao and Sudhof 2001; Guenette 2002). As the apoptotic potential of AICD has been demonstrated, it is likely that APP signaling induces cell death, which leads to AD.

To explore APP signaling, we established embryonic carcinoma P19 cell lines overexpressing AICD (Nakayama et al. 2008b). Although neurons were differentiated from these cell lines with all-trans-retinoic acid (RA) treatment, AICD expression induced neuronspecific apoptosis. The effects of AICD were restricted to neurons, with no effects observed on non-neural cells. Furthermore, we evaluated changes in gene expression induced by AICD during this process of neuron-specific cell death using DNA microarrays (Ohkawara et al. 2011). The results of microarray analysis indicated that AICD induces dynamic changes in the gene expression profile. Therefore, it is likely that APP also has a signaling mechanism and that AICD may play a role in APP signaling, which leads to AD. 
Here, we focus on molecular mechanisms of the Notch-Delta signaling pathway in a bidirectional manner and discuss the possibility that $\gamma$-secretase-regulated mechanisms similar to the Notch-Delta signaling pathway may play a potential role in signaling events involving type 1 transmembrane proteins. In addition, we introduce the current topics of $\gamma$ secretase. We also discuss the possibility that APP signaling induces dynamic changes in gene expression, which may be closely correlated with AICD-induced neuron-specific apoptosis, leading to $\mathrm{AD}$.

\section{Notch}

\subsection{Notch and its ligands}

The typical Notch gene encodes a 300-kD type 1 transmembrane protein with the large extracellular domain which contains about 36 tandem epidermal growth factor (EGF)-like repeats (Wharton et al. 1985). The 11th and 12th EGF-like repeats are necessary and sufficient for binding to its ligands in Drosophila (Rebay et al. 1991). NICD is also large and has six tandem ankyrin-like (CDC10) repeats (Wharton et al. 1985). The fundamental structures are well conserved throughout evolution, although the numbers of EGF-like repeats vary from 10 in C. elegans (Glp-1) (Yochem and Greenwald 1989) to 36 in Drosophila and some vertebrate Notch .

While Drosophila has only one Notch gene, four Notch isoforms (Notch1 to 4) have been found in mammals. TAN1 (Notch1), which is a first identified mammalian homolog of Notch, was cloned as a gene responsible for human T cell acute lymphoblastic leukemia (TALL) (Ellisen et al. 1991). Notch2 was also cloned as an oncogene of cat thymic lymphoma (Rohn et al. 1996). A mutation of the Notch3 gene causes cerebral autosomal dominant arteriopathy with subcortical infarcts and leukoencephalopathy (CADASIL) (Joutel et al. 1996), in which the main symptom is cerebral vascular disorder. Interestingly, Notch4 is a cellular counterpart of the oncogene of mouse mammary tumor virus (int3) and expresses in vascular endothelial cells (Sarkar et al. 1994).

While Drosophila has two different ligands Delta (Kopczynski et al. 1988) and Serrate (Fleming et al. 1990), two families of ligands, Delta family (Delta-like protein: Dll1, 3 and 4) (Bettenhausen et al. 1995; Dunwoodie et al. 1997; Shutter et al. 2000) and Jagged family (Jagged1 and 2) (Lindsell et al. 1995; Shawber et al. 1996), have been identified in mammals to date. C. elegans has two ligands, Lag-2 (Tax et al. 1994) and Apx-1 (Mello et al. 1994). The extracellular domains of all these ligands also contain variable numbers of EGF-like repeats; for example Drosophila Delta has nine, most vertebrate Deltas have eight, and C. elegans Lag2 has two repeats. All of these ligands also share a single copy of a second cysteine-rich conservative motif called the DSL (Delta: Serrate: Lag-2) domain (Tax et al. 1994), which is essential for binding to Notch (Henderson et al. 1997). In addition, spondylocostal dysostosis (SCD), which is characterized by abnormal vertebral segmentation, is caused by mutations of Dll3 gene (Sparrow et al. 2002). Alagille syndrome, which is a multi-system disorder characterized by paucity of bile ducts and congenital heart disease, is associated with a Jagged1 mutation (Oda et al. 1997) as well as a Notch2 mutation (McCright et al. 2002).

ICDs of all ligands are relatively short compared to those of Notch and it was thought that none of ICDs of Notch ligands display any significant sequence similarity throughout 
evolution (Henderson et al. 1994). As described below, structural evidence supports the idea that ICDs of these ligands are non-functional. However, we have revealed that Delta homologues display significant sequence similarity, which is restricted to vertebrates, in their ICDs (Hiratochi et al. 2007). There is no homology between these vertebrate Deltas and Drosophila Delta. In addition, Dll3, a divergent type of Delta, does not show any homology to other Delta in ICD.

\subsection{The molecular mechanism of the Notch signaling pathway}

Fig. 1 shows a diagram of the Notch signaling pathway. In the canonical Notch signaling pathway, ligands bind to the extracellular domain of Notch on neighboring cells. Both Notch (Gupta-Rossi et al. 2004) and its ligands (Itoh et al. 2003) undergo ubiquitin-regulated internalization. Mind bomb (Mib) is essential for efficient activation of Notch signaling in this step. Mib is a RING-type E3 ubiquitin ligase that ubiquitylates ICDs of Notch ligands and promotes internalization of these ligands in a ubiquitination-dependent manner (Itoh $e t$ al. 2003). As a result of these reactions, conformations of Notch and its ligands may be changed by pulling each other to trigger sequential proteolytic cleavages called the regulated intramembrane proteolysis (RIP) mechanism (Brown et al. 2000). The RIP mechanism requires sequential cleavage steps to occur within the juxtamembrane (JM) and TM domains, and these steps are carried out by metalloproteases and $\gamma$-secretase, respectively (Selkoe and Kopan 2003). Since precise steps of Notch processing are recently made clear and those steps are very similar to that of APP, we mentioned about details of these processes in "3.2 Processing mechanisms of several $\gamma$-secretase substrates, such as APP, are very similar to that of Notch."

Finally, $\gamma$-secretase serves to release NICD from the cell membrane to the cytoplasm and released NICD translocates to the nucleus. Thus, $\gamma$-secretase plays a central role in the regulation of Notch signaling. Although NICD has a nuclear localization signal and is accumulated in the nucleus as an activated form of Notch, mechanisms of the transport of NICD from cytoplasm to nucleus have not yet been clarified.

In the nucleus, NICD binds to transcription factors and controls expressions of certain genes. Members of the CSL family (CBF1/RBP-jк in mammals, $\mathrm{Su}(\mathrm{H})$ in Drosophila and Lag-1 in C. elegans) are major downstream transcription factors of Notch signaling (Artavanis-Tsakonas et al. 1995; Kimble and Simpson 1997; Artavanis-Tsakonas et al. 1999). NICD binds to CSL transcription factors; six tandem ankyrin-like repeats lying in NICD are essential for binding to CSL transcriptional factors (Roehl et al. 1996). As NICD also binds to Mastermind-like proteins (MAML family in mammals) (Wu et al. 2000), the CSL-NICD-MAML complex is formed. As a result of forming these complexes, co-repressors are dispersed from CSL and co-activators such as P/CAF and P300 are recruited by these complexes (Wallberg et al. 2002). Therefore, the function of CSL complexes is converted from a transcriptional repressor to an activator. Finally, activated CSL complexes bind to the cis-acting DNA sequences of target genes and enhance the transcriptional activity of these genes.

The most established target genes for Notch signaling are Hes (Hairy/Enhancer of split in Drosophila) genes, which code for the basic helix-loop-helix (bHLH) transcriptional repressor for tissue-specific genes (Kageyama et al. 2007). Seven mammalian Hes, designated Hes1 to Hes7, have been identified to date, although the mouse does not have Hes4. Hes1 and Hes5 
bind to their target DNA sequences called $\mathrm{N}$ box (CACNAG) by forming homodimers or heterodimers with Hey (Hes-related with YRPW motif) 1 or Hey2, and to recruit histone deacetylase (HDAC) activity by associating with Groucho, resulting in transcriptional repression (Akazawa et al. 1992; Leimeister et al. 1999; Iso et al. 2001). Moreover, they associate with E proteins which are ubiquitously expressed bHLH factors and prevent proneural bHLH factors, such as Neurogenin, from forming functional complexes with E protein (Kageyama et al. 2007). In this manner, Notch represses the differentiation of cells to specific lineages. In addition, Delta expression is induced by proneural genes that code for bHLH transcriptional factor, although multiple POU-binding factors are also important for Delta expression in mammalian NSCs (Nakayama et al. 2004). Thus, Notch signaling strongly inhibits Delta expression.

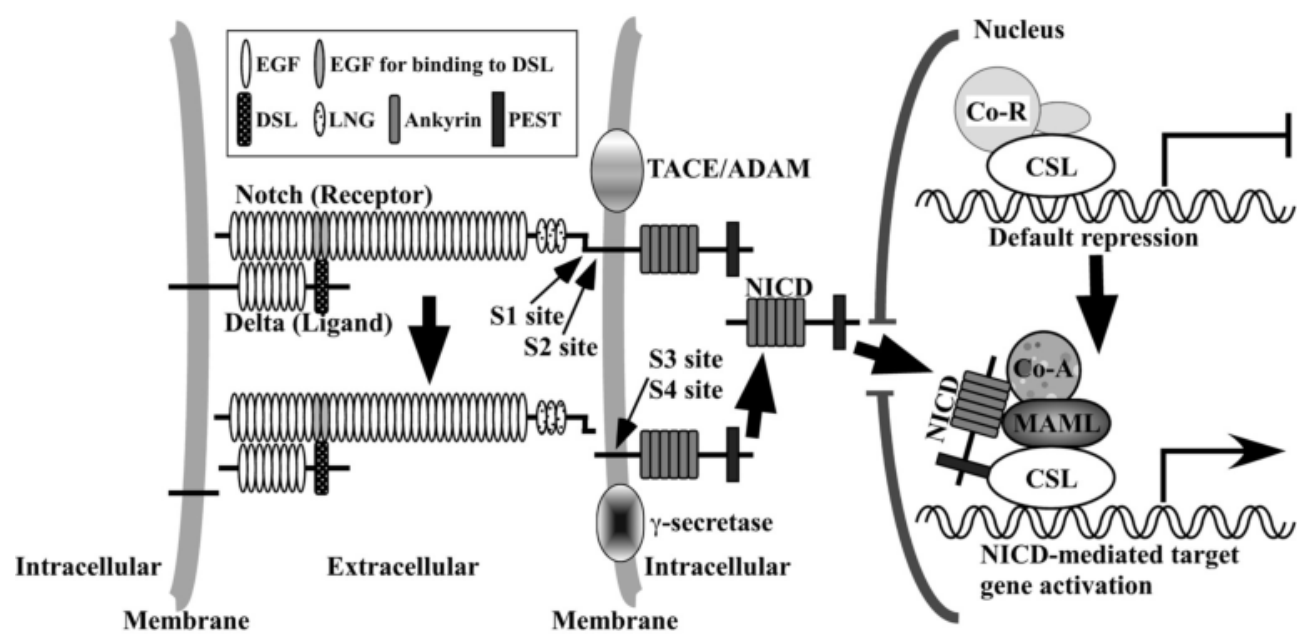

Notch proteins are expressed on the cell surface as heterodimers after cleavage at the S1 site by furin.

The binding of Notch to the ligand triggers sequential proteolytic cleavage of RIP. When Notch binds to the ligand, Notch is cleaved at the S2 site in the juxtamembrane region by TACE or ADAM protease. Next, the remaining protein stub is further cleaved by $\gamma$-secretase at the S3 and S4 sites within the transmembrane domain and NICD is released from the membrane. Then, NICD translocates into the nucleus and binds to the CSL together with MAML. The resultant CSL-NICD-MAML complex removes co-repressors from CSL transcription factor and recruits a co-activator, resulting in conversion from repressor to activator. Finally, the complexes of CSL-NICD-MAML-co-activators promote transcription of the target genes

Fig. 1. Notch signaling pathway.

\subsection{Notch signaling in the differentiation of NSCs}

The definition of NSCs is that cells can self-renew and are capable of differentiating into main phenotypes of the nervous system, such as neurons, astrocytes and oligodendrocytes. In mammals, such cells have been isolated from the developing neural tube and more recently from the adult brain. Although there are some data showing that Notch signaling plays a role in the adult NSCs, a large majority of evidence for Notch signaling in controlling NSCs differentiation comes from analysis of embryonic neurogenesis. 
In the developing mammalian central nervous system, NSCs repeat self-renewal by symmetric cell division to increase the total number of NSCs as a first step (NSCs/progenitor cells expansion phase). In this phase, Notch signaling is thought to maintain those NSCs in the proliferating and undifferentiating state (Fortini 2009; Kopan and Ilagan 2009; Pierfelice et al. 2011). Recently, it has been shown that expression of Hes1, the target genes for Notch signaling, oscillates with a period of about 2 hours in this phase (Kageyama et al. 2007). Hes1 expression may induce the oscillatory expression of Dll1 gene and the proneural Neurogenin2 (Ngn2) gene by periodic repression. Thus, concentrations of Dll1 mRNA and both Ngn2 mRNA and protein also oscillate with an inverse correlation with Hes1 (Kageyama et al. 2008; Shimojo et al. 2011). It is thought that Ngn2 cannot induce differentiation of neuron when Ngn2 expression oscillated and Dll1 leads to the activation of Notch signaling to maintain NSCs in proliferating state.

In next phase (neurogenic phase), NSCs undergo asymmetric cell division, where each NSC divides into two distinct types, NSC and neuron. In this phase, oscillatory expressions of Hes1 disappear (Kageyama et al. 2008; Shimojo et al. 2011). Since Hes1 expression is repressed, Dll1 and Ngn2 are constitutively expressed in a sustained manner and Ngn2 induces neuronal differentiation. Although the role of Notch signaling is not well understood, numb, which is an antagonist of Notch signaling (Frise et al. 1996; Guo et al. 1996; Spana and Doe 1996), is thought to be a critical component of NSCs asymmetrical division. During NSC divisions in this phase, numb appeared to be asymmetrically distributed to the neuronal daughter cells and was absent in undifferentiated NSCs (Zhong et al. 1996; Zhong et al. 1997; Chenn 2005). Thus, these observations suggest that numb inhibits Notch signaling and promotes differentiation to neuron in the neuronal daughter cells. After the generation of neurons, NSCs differentiate into oligodendrocytes and ependymal cells, followed by differentiation into astrocytes (gliogenic phase).

Recently, it has been shown that Notch signaling may also play an essential role in maintenance and differentiation of adult NSCs (Imayoshi and Kageyama 2011). Usually, adult NSCs are in the dormant state (quiescent state) and Notch signaling may maintain this state of adult NSCs. It is thought that NSCs turn from dormant state into dividing state, when the activity of Notch signaling falls down. Thus, Notch signaling controls the balance between dormant state and differentiation state of adult NSCs.

\subsection{Delta signaling may be involved in neuronal differentiation}

The Notch signaling pathway has long been thought to be mono-directional because ligands for Notch were generally considered unable to transmit signals into cells expressing these ligands (Henderson et al. 1994; Fitzgerald and Greenwald 1995). Indeed, it was thought that none of ICDs of putative Notch ligands display any significant sequence similarity throughout evolution (Henderson et al. 1994). Moreover, replacement of most of ICD of LAG-2, a C. elegans lin-12 (Notch) ligand, with a $\beta$-galactosidase fusion protein has no discernible effect on LAG-2 function (Henderson et al. 1994). In contrast, however, it has been reported that the extracellular domain of Notch expressed in the mesoderm provided a positive signal to the overlaying ectoderm in Drosophila as mentioned below (Baker and Schubiger 1996). Since these observations suggest that signaling in the opposite direction also exists, the important and critical question is whether signaling events occur not only from ligand-expressing cells to Notch-expressing cells but also vice versa, i.e., in a bi-directional manner. 
Recently, evidence has been accumulating in support of a functional role of ICD of Notch ligands, which implies the existence of bi-directional signaling mechanisms. For example, Delta has been shown to release ICD from the cell membrane when cleaved by ADAM protease and $\gamma$-secretase (Qi et al. 1999; Ikeuchi and Sisodia 2003; LaVoie and Selkoe 2003; Six et al. 2003). Several groups have reported evidences supporting the nuclear localization of Delta ICD (Bland et al. 2003; LaVoie and Selkoe 2003; Six et al. 2003). These observations suggest that Delta ICD is released from the cell membrane by RIP. Indeed, we have shown that Delta homologues display significant sequence similarity, which is restricted to vertebrates, in their ICDs (Hiratochi et al. 2007). It is likely that conservation of these amino acid sequences reflect the functional importance of Delta ICD.

To clarify the question of whether the Notch-Delta signaling pathway is bi-directional, we investigated the effect of Notch on differentiation of NSCs isolated from mouse embryos (Hiratochi et al. 2007). When NSCs were co-cultured on a monolayer of mouse Dll1expressing COS7 cells, the rate at which neurons emerged was lower than that in controls. As mentioned above, Notch signaling maintains the proliferating and undifferentiating state of NSCs and inhibits the differentiation into neurons (Fortini 2009; Kopan and Ilagan 2009; Pierfelice et al. 2011). Therefore, these observations indicate that Dll1 on COS7 cells generates signals to neighboring NSCs that express Notch and thus activates Notch signaling. Conversely, when NSCs were co-cultured on a monolayer of mouse Notch1expressing COS7 cells, the rate of neurons developing from NSCs was significantly higher than that in control cultures. These results suggest that Notch1 on COS7 cells may also generate signals to neighboring NSCs and these ligands, probably Delta, may then transmit signals into cells expressing them to promote neuronal differentiation. Thus, signaling events may occur not only from Delta-expressing cells to Notch-expressing cells but also vice versa, that is, in a bi-directional manner, during differentiation of NSCs. Indeed, Baker and Schubiger published results from a mosaic experiment in Drosophila, which showed that expression of Notch in the mesoderm of Notch mutant suppressed the ectodermal defects of this mutant (Baker and Schubiger 1996). This effect was inferred to be due to the extracellular domain of the protein and not its signaling function, since activated Notch failed to produce non-autonomous suppression (Baker and Schubiger 1996). These results indicate that the extracellular domain of Notch expressed in the mesoderm sent a positive signal to the overlying ectoderm. Thus, these observations further support the hypothesis that Notch-expressing cells also send a signal to Delta-expressing cells.

\subsection{Delta ICD may modify expression of certain genes}

The nuclear localization of Delta ICD suggests that this domain may have effects on the transcription of a specific target gene similar to NICD. To examine this possibility, we searched for transcriptional factors capable of binding to ICD of Dll1 (Dll1IC) using a new method and identified Smads as a Dll1IC binding transcription factor through the differentiation process of mouse NSCs (Hiratochi et al. 2007).

Smads are transcription factors and have been shown to act as mediators of signaling by the TGF- $\beta$ superfamily. Eight Smads, designated Smad1 to Smad8, have been identified to date in mammal (Miyazawa et al. 2002; Derynck and Zhang 2003). Smad2 and Smad3 are activated by TGF- $\beta$ and activin (Eppert et al. 1996; Zhang et al. 1996; Nakao et al. 1997), while 
Smad1 and Smad5 are major components that are activated by bone morphogenic proteins (BMPs) (Hoodless et al. 1996; Kretzschmar et al. 1997; Suzuki et al. 1997). Although Smad1 and Smad5 did not bind to Dll1IC, Smad2 and Smad3 showed strong binding (Hiratochi et al. 2007). These observations indicate that Dll1IC can modify TGF- $\beta$ /Activin signaling through binding to Smad2 and/or Smad3. However, BMP signaling, which is known to inhibit neurogenesis and to enhance the appearance of astrocytes, may not be affected by DIl1IC, because Dll1IC did not bind to Smad1 or Smad5.

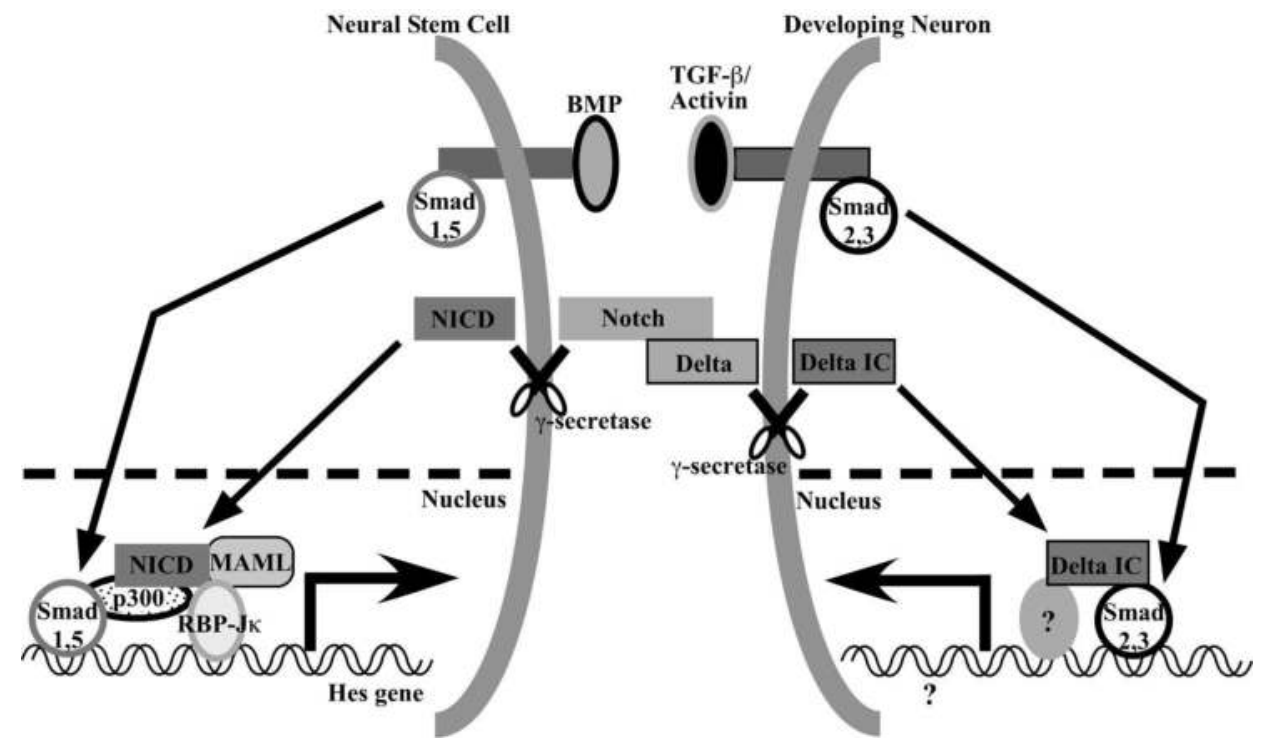

Notch receptor also generates signals to Delta expressed on the surface of neighboring NSCs. Delta is cleaved sequentially by proteases, probably including ADAM and $\gamma$-secretase, and finally the intracellular domain of Delta (DeltaIC) is released from the cell membrane and translocates to the nucleus, where it mediates TGF- $\beta$ / Activin signaling through binding to Smad2/3 and enhances transcription of specific genes leading to neuronal differentiation. It is well known that NICD is also released from the cell membrane by proteases similar to the ones involved in the cleaving of Delta, then translocates to the nucleus to modulate gene expression through binding to the transcription factor, that is, Suppressor of Hairless $(\mathrm{Su}(\mathrm{H}), \mathrm{RBP}-\mathrm{j} \kappa$ in mammals) together with MAML. This means that similar mechanisms are involved in both directions of the bi-directional Notch-Delta signaling pathway. BMPs, another group belonging to the TGF- $\beta$ superfamily, have recently been shown to inhibit neurogenesis and to enhance the generation of astrocytes from NSCs. It has also been demonstrated that NICD and activated Smad1 $/ 5$ form a complex with p300 in the specific promoter sequence, which contains both the RBP-jк and Smad binding sequences. It is therefore possible that the TGF- $\beta$ superfamily mediates both neurogenesis and gliogenesis from NSCs coupled with the bi-directional Notch-Delta signaling pathway.

Fig. 2. Schematic of the bi-directional model of Notch-Delta signaling pathway in the process of NSC differentiation.

Although we have yet to determine the actual target genes for the Dll1IC-Smad complex, we showed that binding of Dll1IC to Smad enhanced its transcriptional activity using the 9XCAGA-Luc promoter-reporter system that responds specifically to Smad3 (Dennler et al. 1998; Jonk et al. 1998), as a model system. These results strongly suggest that Dll1IC 
mediates transcription of certain genes, which are targets of TGF- $\beta$ /Activin signaling, through binding to Smad2 and/or Smad3.

As mentioned above, it is likely that Delta transmits signals into NSCs expressing them to promote neuronal differentiation. To test this possibility, we established embryonic carcinoma P19 cells stably overexpressing Dll1IC (Hiratochi et al. 2007). Although control P19 cells have been shown to be induced to differentiate into neurons, RA stimulation is essential for the induction of neurons from these P19 cells. However, neurons could be induced from P19 cells stably overexpressing Dll1IC without RA stimulation and this induction was strongly inhibited by SB431542, a specific inhibitor of TGF- $\beta$ type1 receptor (Laping et al. 2002) that activates Smad2 and Smad3. These results suggest that overexpression of Dll1IC in P19 cells induced neurons through binding to Smad2 and/or Smad3. Therefore, it is highly possible that Delta signaling also plays an important role in neuronal differentiation. Recently, it has been reported that TGF- $\beta$ inhibits proliferation and accelerates differentiation of the hippocampal granule neuron (Lu et al. 2005). This observation also supports our hypothesis.

A schematic model of Notch-Delta signaling pathway in the process of NSC differentiation is shown in Fig. 2.

\section{3. $\gamma$-Secretase}

\subsection{Overview of $\gamma$-secretase}

$\gamma_{-}$Secretase was first identified as a protease that cleaves APP within the TM domain and produces A $\beta$ peptides (Haass and Selkoe 1993), which are thought to have pathogenic roles in AD. However, the physiological functions of this enzyme have not been clarified (Kopan and Ilagan 2004; Selkoe and Wolfe 2007). The $\gamma$-secretase is a complex composed of PS, nicastrin (NCT), anterior pharynx defective-1 (Aph-1), and PS enhancer-2 protein (Pen-2) (Iwatsubo 2004; Kopan and Ilagan 2004; Selkoe and Wolfe 2007). PS is a catalytic component of the $\gamma$-secretase complex, and the two PS genes, PS1 gene (PSEN1) (Sherrington et al. 1995) located on chromosome 14 and PS2 gene (PSEN2) (Levy-Lahad et al. 1995; Rogaev et al. 1995) located on chromosome 1, were identified by genetic linkage analyses as the genes responsible for several forms of early-onset familial AD (FAD). PSEN1 and PSEN2 encode polytopic transmembrane proteins of 467 and 448 amino acids, respectively, which show about $65 \%$ sequence identity between the two proteins. While PS1 expression level is higher than that of PS2, both proteins are expressed ubiquitously in the brain and peripheral tissues of adult mammals (Lee et al. 1996). The model for PS with eight or nine transmembrane domains is generally accepted and PS has a hydrophilic loop domain between the putative 6th and 7th transmembrane domains facing the cytoplasm (Doan et al. 1996) and is cleaved by an unidentified protease within this loop resulting into two fragments, N- and Cterminal fragment (NTF and CTF), that remain associated as a heterodimer (Thinakaran et al. 1996). This proteolytic cleavage is thought to occur when nascent PS assembles with NCT, Aph-1, and Pen-2 as a $\gamma$-secretase complex and activates PS as the catalytic component of aspartyl protease (Iwatsubo 2004; Kopan and Ilagan 2004; Selkoe and Wolfe 2007).

The single-pass membrane protein NCT may recognize the substrate proteins of $\gamma$-secretase (Yu et al. 2000; Shah et al. 2005). The extracellular domain of NCT resembles an aminopeptidase, but lacks catalytic residues, and can interact with the N-terminal stubs of $\gamma$ - 
secretase substrates after ectodomain shedding (Shah et al. 2005). Thus, shedding of membrane proteins may be essential for the production of free $\mathrm{N}$-termini of these proteins retained in the membrane, which can then be recognized by NCT. Aph-1 is thought to act as a scaffold during the process of $\gamma$-secretase complex assembly, and Pen- 2 was suggested to act as a trigger for the proteolytic cleavage of PS to regulate PS activity (Kopan and Ilagan 2004; Selkoe and Wolfe 2007).

\subsection{Processing mechanisms of several $\gamma$-secretase substrates, such as APP, are very similar to that of Notch}

Precise steps of Notch processing are recently made clear (Fig.3). After translation, Notch is cleaved by furin-like covertase at the S1 site in the trans-Golgi network, and the two resulting fragments remain associated to form a functional heterodimer that is expressed on the cell surface (Logeat et al. 1998).

A) Notch

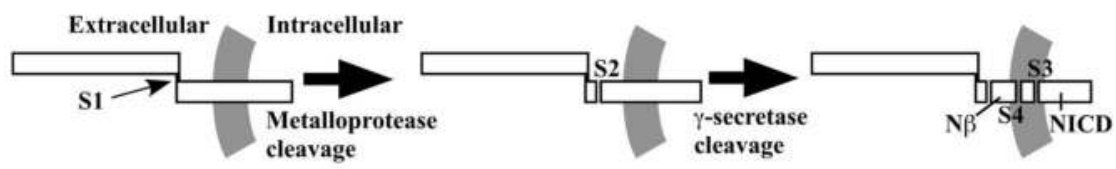

B) APP

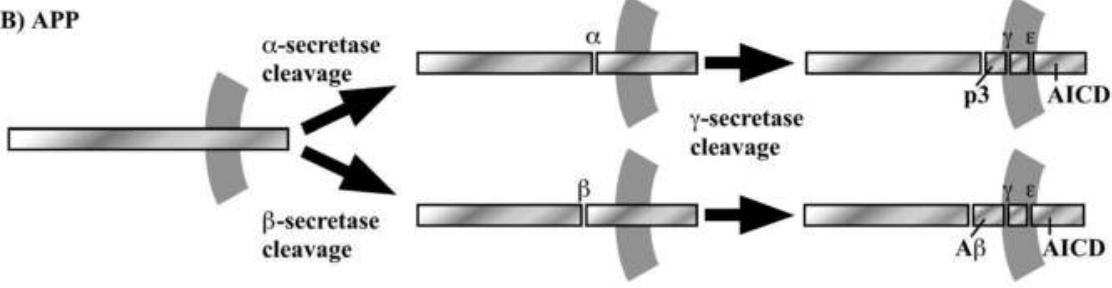

C) $\mathrm{CD} 44$

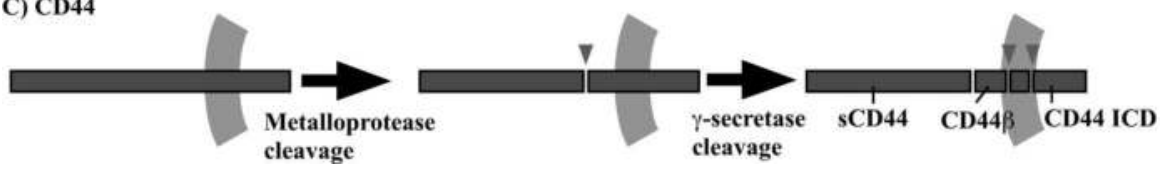

(A) In response to ligand binding, Notch undergoes shedding due to metalloprotease cleavage at the S2 site within the JM domain. After shedding the extracellular domain, the remaining Notch stub is further cleaved by $\gamma$-secretase at S3 and S4 sites within the TM domain. This sequential proteolysis produces NICD and N $\beta$ fragment. (B) Cleavage of APP by $\alpha$-secretase or $\beta$-secretase at the $\alpha$-site or $\beta$-site, respectively, within the JM domain results in shedding of almost the entire extracellular domain and generates membrane-tethered $\alpha$ - or $\beta$-carboxy terminal fragments (CTFs). Several zinc metalloproteinases and BACE2 can cleave APP at the $\alpha$-site, while BACE1 cleaves APP at the $\beta$-site. After shedding the extracellular domain, the remaining stub is further cleaved at least twice within the TM domain at $\gamma$ - and $\varepsilon$-sites by $\gamma$-secretase, producing either p3 peptide (in combination with $\alpha$ secretase) or A $\beta$ (in combination with BACE1), respectively, and AICD. (C) Several stimuli, such as PKC activation and $\mathrm{Ca}^{2+}$ influx, trigger ectodomain cleavage of CD44 by a metalloprotease at the site within the JM domain, resulting in the secretion of soluble CD44 (sCD44). After shedding the extracellular domain, the remaining CD44 stub is further cleaved by $\gamma$-secretase at two sites within the TM domain. This sequential proteolysis produces the CD44 ICD and CD44 $\beta$, an A $\beta$-like peptide.

Fig. 3. Similarities in the proteolytic processes among Notch, APP, and CD44. 
As mentioned above, the sequential proteolytic cleavage called RIP mechanism is initiated by ligand binding and shedding at the S2 site by TACE or ADAM protease making the truncated Notch (Pan and Rubin 1997; Brou et al. 2000). Truncated Notch is further cleaved by $\gamma$-secretase in at least two sites within the TM domain, i.e., at the S3 site to release NICD and at the S4 site to release the remaining small peptide (NB) (Kopan et al. 1996; Schroeter et al. 1998; Okochi et al. 2002), which resembles A $\beta$.

The proteolytic process of APP resembles that of Notch and also follows the RIP mechanism (Fig.3). Cleavage of APP by $\alpha$-secretase (Esch et al. 1990) or $\beta$-secretase (Vassar et al. 1999) at the $\alpha$-site or $\beta$-site, respectively, within the JM region results in shedding of almost the entire extracellular domain and generates membrane-tethered $\alpha$ - or $\beta$-CTFs. Several zinc metalloproteinases (Buxbaum et al. 1998; Lammich et al. 1999) and the aspartyl protease BACE2 can cleave APP at the $\alpha$-site (Farzan et al. 2000), while BACE1 ( $\beta$-site APP cleaving enzyme) cleaves APP at the $\beta$-site (Vassar et al. 1999). After shedding, the remaining stub is further cleaved at least twice by $\gamma$-secretase within the TM domain at $\gamma$ - and $\varepsilon$-sites resulting in production of either non-amyloidogenic p3 peptide (in combination with $\alpha$-secretase) or amyloidogenic $A \beta$ (in combination with BACE1), respectively, and AICD (Kopan and Ilagan 2004; Selkoe and Wolfe 2007). In addition, AICD was shown to be a substrate of caspase and to be cleaved at the group III caspase consensus sequence 16 amino acids from the membrane border within the AICD.

It has been reported that several $\gamma$-secretase substrates also follow the RIP mechanism with release of their ICDs from the cell membrane. As shown in Fig. 3, the process of sequential proteolytic cleavage of CD44, which is important for immune system function, is very similar to those of Notch and APP and follows the RIP mechanism (Nagase et al. 2011). In addition, the ICD of this protein (CD44ICD) is also translocated to the nucleus, suggesting that CD44ICD may also mediate the gene expression.

\subsection{Does $\gamma$-secretase mediate signaling events of type 1 transmembrane proteins?}

$\gamma$-Secretase seems to cleave a diverse set of type1 transmembrane proteins, which have been shed their extracellular domains, in a sequence-independent manner (Struhl and Adachi 2000). As reflected by the flexible sequence specificity of $\gamma$-secretase activity, more than 50 type 1 transmembrane proteins have been reported as substrates of $\gamma$-secretase (McCarthy et al. 2009). As shown in Table 1, these substrates also have a wide range of functions, including roles in cell differentiation (Notch, Delta, and Jagged), cell adhesion (N-cadherin, E-cadherin, and CD44), synaptic adhesion (Nectin-1 $\alpha$ ), ion conductance regulation (voltagegated sodium channel $\beta 2$ subunit), axon guidance and tumor suppression (DCC), neurotrophin receptor (P75NTR), and its homolog (NRADD), lipoprotein receptor (ApoER2), and growth factor-dependent receptor tyrosine kinase (ERBB4).

As mentioned above, proteolytic cleavages of several $\gamma$-secretase substrates, such as APP and CD44, follow the RIP mechanism. The ICDs of these substrates are released from the cell membrane to cytoplasm by $\gamma$-secretase, and finally these ICDs translocate to the nucleus. These processes are very similar to those involved in Notch signaling. Thus, the observations that the common enzyme, $\gamma$-secretase, modulates proteolysis and the turnover of possible signaling molecules led to the signaling hypothesis suggesting that mechanisms similar to those 
occurring in the Notch signaling pathway may contribute widely to $\gamma$-secretase-regulated signaling pathways (Koo and Kopan 2004; Nakayama et al. 2008a; Nakayama et al. 2011).

Indeed, as mentioned above, Dll1 is cleaved sequentially by proteases, probably including ADAM and $\gamma$-secretase, and DIl1IC is released from the cell membrane and undergoes translocation to the nucleus (Hiratochi et al. 2007). In the nucleus, Dll1IC enhances transcription of specific genes through binding to Smads. These observations suggest that Dll1 may also have a signaling mechanism similar to Notch signaling.

Substrate

ApoER2

APP

APLP1/2

E-cadherin

$\mathrm{N}$-cadherin

$\beta$-catenin

CD43

CD44

CSF1-R

CXCL16 \& CX3CL

DCC

Delta

ERBB4

HLA-A2

IGIF-R

IFN- $\alpha$ R2

IL-1RI

IL-1RII

Jagged

LDLR

LRP

Na channel $\beta$ subunit

Nectin-1 $\alpha$

\section{Function}

Lipoprotein receptor, neuronal migration

Precursor to $A \beta$, adhesion, trophic properties, axonal transport?

Cell adhesion?

Cell adhesion

Cell adhesion

Transduce Wnt signals stabilize adherens junctions

Signal transduction

Cell adhesion

Protein tyrosine kinase

ligands

Axon guidance, tumor

suppressor

Notch ligand

Receptor tyrosine kinase

MHC class I molecule

Receptor tyrosine kinase

Subunit of type I IFN- $\alpha$

receptor

Cytokine receptor

Cytokine receptor

Notch ligand

Lipoprotein receptor

Scavenger and signaling receptor

Cell adhesion, an auxiliary subunit of voltage-gated $\mathrm{Na}$ channel

Adherens junction, synapse receptor
PS or ICD function

Activate nuclear reporter

$\mathrm{A} \beta$ generation, release of ICD, complex with Fe65/Tip60, Cell death?

Form complex with Fe65 and Tip60

Promote disassembly of adhesion complex

Promote CBP degradation

Facilitate phosphorylation

Signaling molecule?

Activate TRE-mediated nuclear transcription

Unknown

Unknown

Activate nuclear reporter

Transcription regulation

Regulate heregulin-induced growth inhibition

Unknown

Unknown

Transcriptional regulation

Unknown

Unknown

Modulate AP-1 mediated transcription

Unkown

Activate nuclear reporter

Alter cell adhesion and migration

Remodeling of cell junctions? 


\begin{tabular}{|c|c|c|}
\hline Substrate & Function & PS or ICD function \\
\hline Notch1-4 & Signaling receptor & Transcription regulation \\
\hline NRADD & Apoptosis in neuronal cells & $\begin{array}{l}\text { Modulate glycosylation/matutaion of } \\
\text { NRADD }\end{array}$ \\
\hline P75NTR & $\begin{array}{l}\text { Neurotrophin co-receptor, } \\
\text { dependence receptor }\end{array}$ & $\begin{array}{l}\text { Modulate p75-TrkA complex? } \\
\text { Nuclear singaling? }\end{array}$ \\
\hline$\gamma$-protocadherin & $\begin{array}{l}\text { Cell adhesion, neuronal } \\
\text { differentiation }\end{array}$ & Regulation of gene transcription? \\
\hline Syndecan-3 & $\begin{array}{l}\text { Cell surface proteoglycan co- } \\
\text { receptor }\end{array}$ & $\begin{array}{l}\text { Regulation of membrane-targeting of } \\
\text { CASK }\end{array}$ \\
\hline Telencephalin & Cell adhesion & Turnover of telencephalin \\
\hline $\begin{array}{l}\text { Tyrosinase, } \\
\text { Tyrosinase-related } \\
\text { protein } 1 / 2\end{array}$ & Pigment synthesis & $\begin{array}{l}\text { Intracellular transport of Post-Golgi Tyr- } \\
\text { containing vesicles }\end{array}$ \\
\hline
\end{tabular}

PS, presenilin; ICD, intracellular domain; APLP, APP like protein; CBP, CREB (cAMP-responsive element binding protein)-binding protein; TRE, TPA (12-o-tetradecanoylphorbol 13-acetate)-responsive element; AP-1, activator protein-1; CASK, calmodulin-dependent serine kinase; Tyr, Tyrosinase.

Table 1. Substrates for $\gamma$-secretase

\subsection{Is $\gamma$-secretase a proteasome of the membrane?}

As mentioned above, more than 50 type 1 membrane proteins have been reported as substrates of $\gamma$-secretase. This observation raises the simple question of why so many membrane proteins can transmit signals to the nucleus. In contrast to the signaling hypothesis, Kopan and Ilagan proposed another possibility that $\gamma$-secretase may act as a proteasome for membrane proteins (Kopan and Ilagan 2004). They pointed out that generally the ICDs of these substrates including AICD, which are released by $\gamma$-secretase, are rapidly degraded. Moreover, ectodomain shedding seems to be constitutive for some substrates, and ligand binding has been reported to enhance only intramembrane cleavage of Notch (Schroeter et al. 1998), Delta (Hiratochi et al. 2007), Syndecan-3 (Schulz et al. 2003), and ERBB4 (Ni et al. 2001). In addition, they also pointed out that the most evidence supporting the signaling hypothesis was obtained in overexpression experiments that differ somewhat from physiological conditions. Based on these observations, they proposed the proteasome hypothesis that the primary function of $\gamma$-secretase is to facilitate the selective disposal of type 1 membrane proteins (Kopan and Ilagan 2004).

While the proteasome hypothesis of $\gamma$-secretase is reasonable, there is no doubt that $\gamma$ secretase regulates signaling pathways of some substrates, such as Notch (ArtavanisTsakonas et al. 1999; Selkoe and Kopan 2003; Koo and Kopan 2004). Although further studies are required to elucidate this issue, it is likely that $\gamma$-secretases are not uniform complexes but that different $\gamma$-secretase complexes may exist in different combinations with components such as Aph-1, Pen2, and/or PS isoforms, with different cellular functions, such as roles in signaling or degradation (Kopan and Ilagan 2004). Since $\gamma$-secretase substrates such as APP are generally more abundant than transcription factors, which are usually rare molecules, it is uncertain whether the majority of the ICDs of these substrates released by $\gamma$ secretase are required for the signaling mechanisms (Nakayama et al. 2008a; Nakayama et al. 
2011). Although a large proportion of ICDs of these substrates are rapidly degraded, it is likely that a small amount of the remaining ICDs may be suitable for their functions with a small quantity of transcription factors. Thus, the greater part of ICDs of these substrates may be degraded and only a small proportion may play a role in signaling.

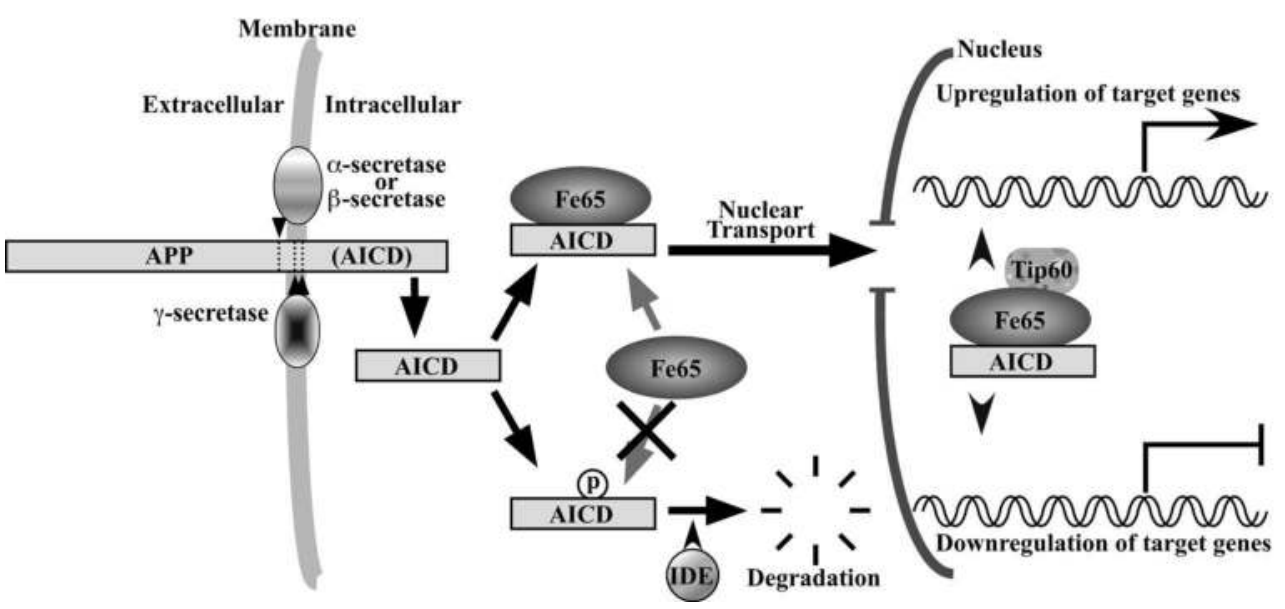

After cleavege of JM domain by $\alpha$ - or $\beta$-secretase, AICD is released from the membrane by $\gamma$-secretase. Non-phosphorylated AICD binds to the nuclear adaptor protein Fe65, which is thought to be essential for translocation of AICD to the nucleus, and forms complexes, alone or with the histone acetyltransferase Tip60. These complexes can immediately translocate to the nucleus, where they meidate up- and downregulation of certain target genes in association with Tip60. On the other hand, phospholylated AICD cannot translocate to the nucleus due to the inhibition of binding to Fe65, leading to rapid degradation by the proteasome and/or insulin-degrading enzyme (IDE).

Fig. 4. Putative APP signaling pathway.

In relation to this issue, an attractive model has been proposed (Fig.4) (Buoso et al. 2011). Binding to nuclear adaptor protein Fe65 is thought to be essential for translocation of AICD to the nucleus. In this model, since non-phosphorylated AICD binds to Fe65 and forms complexes, these complexes can immediately translocate to the nucleus, where they control the expression of certain genes in association with the histone acetyltransferase Tip60. On the other hand, as other stimuli induce phosphorylation of AICD, which strongly inhibits binding to Fe65, AICD without Fe65 cannot translocate to the nucleus. Phosphorylated AICD left in the cytosol is rapidly degraded, most likely by the proteasome and/or insulin-degrading enzyme (IDE) (Edbauer et al. 2002). Indeed, it has been reported that when phosphorylated at Thr668 in the APP-695 isoform, AICD cannot bind to Fe65 (Kimberly et al. 2005).

\section{APP signaling?}

\subsection{Overview of APP}

APP was first identified as a cDNA cloned using a partial amino acid sequence of A $\beta$ fragment from the amyloid plaque of AD brains (Kang et al. 1987). APP is a type 1 membrane protein expressed in many tissues, especially concentrated in the synapses of 
neurons. In humans, the APP gene contains at least 18 exons in a total length of $240 \mathrm{~kb}$ (Yoshikai et al. 1990), and several alternative splicing isoforms of APP have been observed, differing mainly in the absence (APP-695 which is predominately expressed in neurons) or presence (APP-751 and APP-770) of a Kunitz protease inhibitor (KPI) domain located toward the N-terminus of the protein (Sisodia et al. 1993). As mentioned above, APP undergoes sequential proteolytic cleavage reactions to yield the extracellular fragment, intracellular fragment (AICD), and A $\beta$ fragment located in the membrane-spanning domain, which is thought to be the main cause of the onset of AD.

While APP has central roles in AD (Hardy 1997; Selkoe 2001), the physiological functions of this protein also remain to be clarified (Zheng and Koo 2006). It has been reported that APP acts as a cell adhesion molecule for cell-cell interaction (Soba et al. 2005), and as a neurotrophic and/or synaptogenic factor (Hung et al. 1992; Bibel et al. 2004; Leyssen et al. 2005). In addition, the possibility that APP is a cell-surface receptor is interesting from the signaling perspective. Several evidences support this idea; e.g., A $\beta$ can bind to APP and thus may be a candidate ligand for APP (Lorenzo et al. 2000). It has also been reported that Fspondin (Ho and Sudhof 2004) and Nogo-66 receptor (Park et al. 2006) could bind to the extracellular domain of APP and regulate A $\beta$ production. Furthermore, the extracellular domain of APP may potentially interact in trans suggesting that APP molecules can bind to each other (Wang and Ha 2004).

APP homologs show significant evolutionary sequence conservation in ICD (Nakayama et al. 2008b), which may reflect the functional importance of AICD. However, the A $\beta$ region of this protein is not well conserved across species. As mentioned, AICD is thought to form complexes with Fe65 and these complexes translocate to the nucleus. In the nucleus, these complexes may associate with Tip60 and may bind to the cis-acting DNA sequence of the tetraspanin protein KAI1 gene to control transcriptional activity (Baek et al. 2002).

\subsection{AICD induces neuron-specific apoptosis}

There is accumulating evidence in support of the idea that APP signaling exists and contributes to the onset of AD. For example, transgenic mice overexpressing both AICD and Fe65 showed abnormal high activity of glycogen synthase kinase 3 beta (Gsk3b protein) (Ryan and Pimplikar 2005), leading to hyperphosphorylation and aggregation of TAU, resulting in microtubule destabilization, and reduction of nuclear $\beta$-catenin levels causing a loss of cell-cell contact mechanisms that may give rise to neurodegeneration in AD brain. In addition, it was also shown that $\mathrm{c}-\mathrm{Abl}$ modulates AICD-dependent transcriptional induction, as well as apoptotic responses (Vazquez et al. 2009). Interestingly, elevated AICD levels have also been observed in AD brains (Ghosal et al. 2009). Therefore, it is highly possible that APP signaling changes expression patterns of certain genes and induces cell death, which may lead to AD pathology.

To explore APP signaling, we established several AICD-overexpressing embryonic carcinoma P19 cell lines (Nakayama et al. 2008b). Although neurons were differentiated from these cell lines after aggregation culture with RA treatment, AICD expression induced neuron-specific cell death. Indeed, while neurons from control cells which carried vector alone were healthy, almost all neurons from AICD-overexpressing P19 cells showed severe degeneration four days after induction of differentiation (Fig. 5). Moreover, DNA 
fragmentation was detected, and all of terminal deoxynucleotidyl transferase (TdT)mediated deoxyuridine triphosphate (dUTP)-biotin nick end-labeling (TUNEL)-positive cells were also Tuj1-positive neurons. Based on these observations, we concluded that AICD can induce neuron-specific apoptosis (Nakayama et al. 2008b). The effects of AICD were restricted to neurons, with no effects observed on non-neural cells. Thus, although further studies are required, these results strongly suggest that AICD plays a role in APP signaling, which leads to the onset of AD.

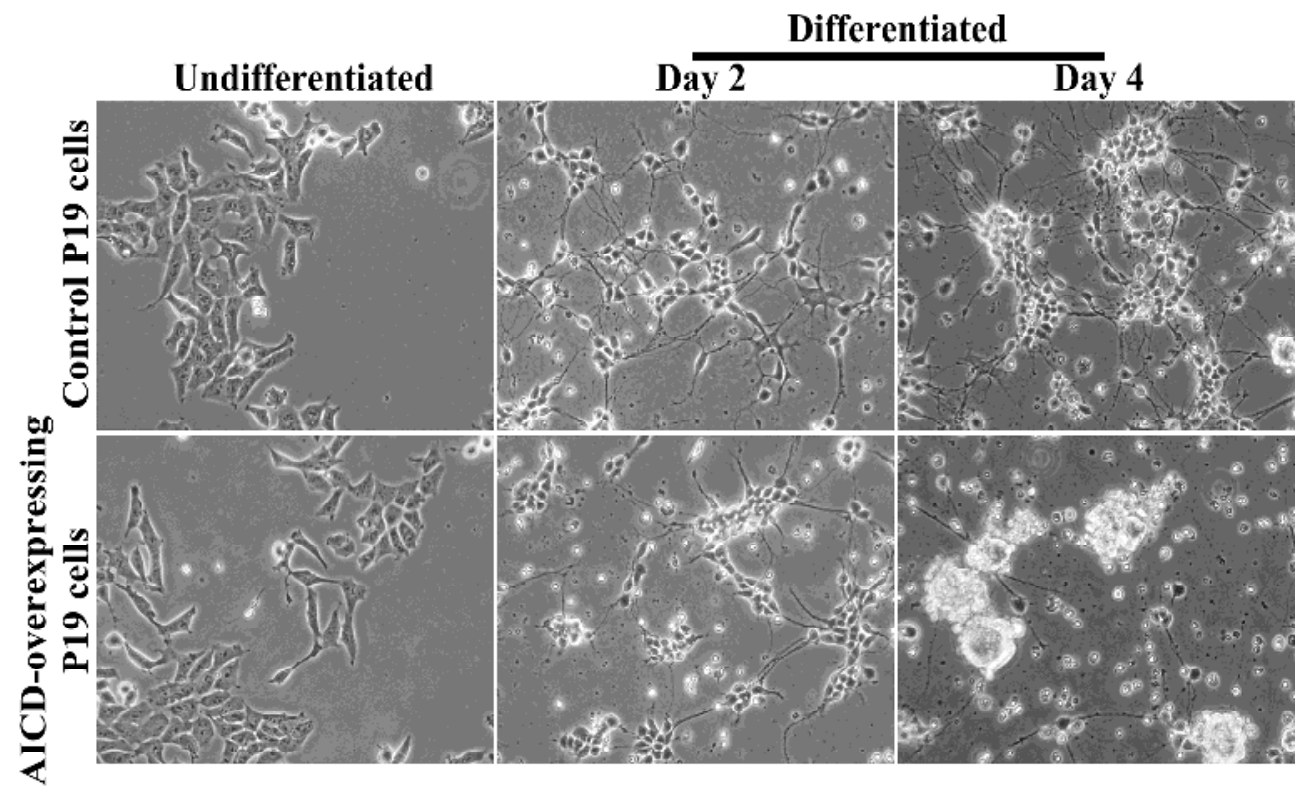

After aggregation culture with RA, AICD-overexpressing P19 and control P19 cells carrying vector alone were replated and cultured for the indicated periods on dishes and allowed to differentiate. Undifferentiated AICD-overexpressing P19 cells retained epithelial cell-like morphology similar to control cells, while the differentiated cells became round and showed a bipolar morphology with neurite extension. Two days after replating (Day 2), all cell lines grew well and neurons with long neurites appeared. Four days after replating (Day 4), control cells still grew well as clusters and many neurons had differentiated from these cells. However, many AICD-overexpressing P19 cells showed severe degeneration, becoming spherical with numerous vacuoles and detached from the culture dishes.

Fig. 5. Overexpression of AICD in P19 cells induces neuronal cell death.

\subsection{AICD induces dynamic changes in the gene expression profile}

If APP signaling exists, AICD should change expression of certain genes. To test this hypothesis and identify the genes involved in this process of neuron-specific apoptosis, we employed both AICD-overexpressing P19 cells and control P19 cells again and monitored AICD-induced changes in expressions of more than 20,000 independent genes by DNA microarray analysis at 3 time points during culture: the undifferentiated state, after 4 days of aggregation with RA (aggregated state), and 2 days after replating (differentiated state) (Ohkawara et al. 2011). Surprisingly, AICD can change expressions of a great many genes: 
the expression levels of 277 genes were upregulated by more than 10-fold in the presence of AICD, while 341 genes showed downregulation of expression to less than $10 \%$ of the original level (Fig.6).

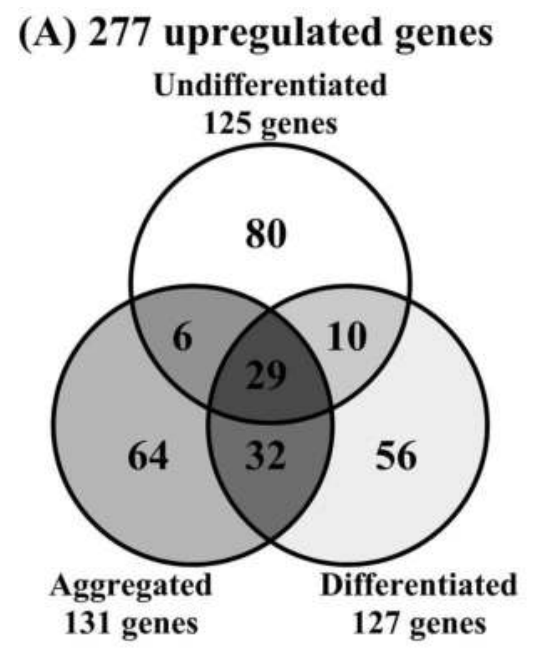

(B) 341 downregulated genes

Undifferentiated

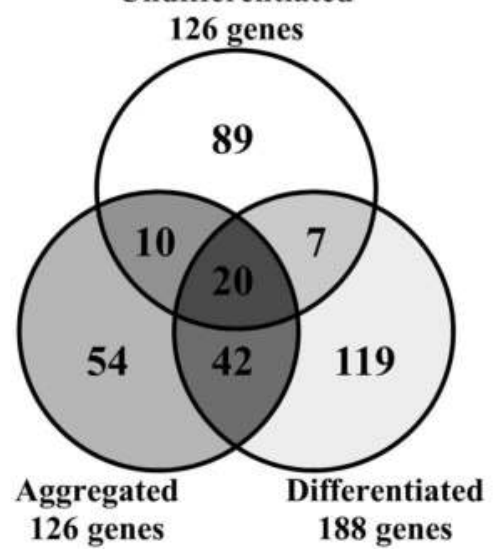

Venn diagrams showing the total numbers of genes upregulated by more than 10 -fold in the presence of $\operatorname{AICD}(\mathrm{A})$ and genes downregulated to less than $10 \%$ of their original level (B) at three states of neural differentiation in P19 cells: undifferentiated, aggregated, and differentiated.

Fig. 6. Upregulated and downregulated genes by AICD.

AICD strongly induced expressions of several genes. For example, AICD-overexpressing P19 cells showed strong expression of protein tyrosine phosphatase receptor T (Ptprt) gene at all sampling points: 906-fold, 204-fold, and 116-fold upregulation, in undifferentiated, aggregated, and differentiated states, respectively, estimated from the intensity of 
hybridization signals. In contrast to these upregulated genes, AICD also strongly inhibited the expression of several genes (Ohkawara et al. 2011). For example, Hes5 was markedly increased through the process of neural differentiation: an increase of almost 300-fold in control P19 cells. However, this extreme induction in control P19 cells could not be detected in AICD-overexpressing P19 cells, indicating that AICD inhibits this induction. These results show that AICD induces both upregulation and downregulation of many genes, suggesting that AICD plays an important role in APP signaling.

We performed Gene Ontology (GO) analysis and classified these upregulated and downregulated genes according to GO terms (Ohkawara et al. 2011). While a few genes were classified into GO terms related to cell death, many genes were classified into GO terms unrelated to cell death. Furthermore, we evaluated AICD-induced changes in expression of genes thought to be involved in cell death in $\mathrm{AD}$; however, we found no significant changes in expression of these genes. Therefore, it is likely that AICD does not directly induce the expression of genes involved in cell death, but the extreme dynamic changes in gene expression disrupt the homeostasis of certain neurons and thus give rise to neuron-specific cell death.

\subsection{Amyloid hypothesis}

Genetic studies indicate that both APP itself and its proteolytic processing are responsible for the onset of AD (Nakayama et al. 2011). The amyloid hypothesis is generally accepted as the mechanism of the onset of AD. The traditional amyloid hypothesis is that overproduced $A \beta$ forms insoluble amyloid plaques, which are commonly observed in the $\mathrm{AD}$ brain and are believed to be the toxic form of APP responsible for neurodegeneration (Hardy and Selkoe 2002).

However, several issues have been raised regarding these hypotheses. One of the most significant arguments against the amyloid hypothesis is the presence of high levels of A $\beta$ deposition in many non-demented elderly people (Terry RD 1999). This observation implies that $\mathrm{A} \beta$ amyloid plaques are not toxic. Based on these observations, the interesting possibility has been proposed that AD may be caused by an APP-derived protein, other than $A \beta$ (Schnabel 2009). As both extracellular fragment and AICD are generated the same time as $A \beta$, acceleration of proteolytic processing leads to overproduction of not only $A \beta$ but also of both extracellular fragment and AICD. Therefore, it is likely that neuron-specific apoptosis induced by AICD may also be involved in the onset of AD.

\section{Conclusion}

Although $\gamma$-secretase plays central roles in $\mathrm{AD}$, the physiological functions of this enzyme have yet to be fully elucidated. As reviewed here, Notch signaling is controlled by $\gamma$ secretase: intramembrane cleavage of Notch by $\gamma$-secretase serves to release ICD that has activity in the nucleus through binding to transcription factors. Recently, it was reported that many type 1 transmembrane proteins are substrates for $\gamma$-secretase, and ICDs of these substrates are released from the cell membrane by $\gamma$-secretase. These observations that the common enzyme, $\gamma$-secretase, modulates proteolysis and the turnover of possible signaling 
molecules have led to the attractive hypothesis that mechanisms similar to the Notch signaling pathway may widely contribute to $\gamma$-secretase-regulated signaling pathways. Indeed, APP signaling induces dynamic changes in gene expression, which may be closely correlated with AICD-induced neuron-specific apoptosis and the onset of AD. Thus, it is likely that $\gamma$-secretase controls Notch signaling in NSCs and APP signaling in neurons that may lead to the onset of AD.

\section{Abbreviations}

$\begin{array}{ll}\text { AD } & \text { Alzheimer's disease } \\ \text { APP } & \text { amyloid precursor protein } \\ \text { AICD } & \text { the intracellular domain of APP } \\ \text { Aph-1 } & \text { anterior pharynx defective-1 } \\ \text { bHLH } & \text { basic helix-loop-helix } \\ \text { BMP } & \text { bone morphogenic protein } \\ \text { CTF } & \text { C-terminal fragment } \\ \text { Dll } & \text { Delta-like protein } \\ \text { Dll1IC } & \text { the intracellular domain of Dll1 } \\ \text { EGF } & \text { epidermal growth factor } \\ \text { FAD } & \text { familial AD } \\ \text { GO } & \text { gene ontology } \\ \text { Hes } & \text { Hairy/Enhancer of split } \\ \text { ICD } & \text { intracellular domain } \\ \text { IDE } & \text { insulin-degrading enzyme } \\ \text { JM } & \text { juxtamembrane } \\ \text { Mib } & \text { Mind bomb } \\ \text { NCT } & \text { nicastrin } \\ \text { Ngn2 } & \text { Neurogenin2 } \\ \text { NICD } & \text { the intracellular domain of Notch } \\ \text { NSC } & \text { neural stem cell } \\ \text { NTF } & \text { N-terminal fragment } \\ \text { Pen-2 } & \text { PS enhancer-2 } \\ \text { PS } & \text { presenilin } \\ \text { RA } & \text { all-trans-retinoic acid } \\ \text { RIP } & \text { the regulated intramembrane proteolysis } \\ \text { TM } & \text { transmembrane }\end{array}$

\section{References}

Akazawa, C., Y. Sasai, S. Nakanishi and R. Kageyama (1992) Molecular characterization of a rat negative regulator with a basic helix-loop-helix structure predominantly expressed in the developing nervous system. J Biol Chem. 267, 21879-85.

Artavanis-Tsakonas, S., K. Matsuno and M. E. Fortini (1995) Notch signaling. Science. 268, 225-32.

Artavanis-Tsakonas, S., M. D. Rand and R. J. Lake (1999) Notch signaling: cell fate control and signal integration in development. Science. 284, 770-6. 
Baek, S. H., K. A. Ohgi, D. W. Rose, E. H. Koo, C. K. Glass and M. G. Rosenfeld (2002) Exchange of N-CoR corepressor and Tip60 coactivator complexes links gene expression by NF-kappaB and beta-amyloid precursor protein. Cell. 110, 55-67.

Baker, R. and G. Schubiger (1996) Autonomous and nonautonomous Notch functions for embryonic muscle and epidermis development in Drosophila. Development. 122, 617-26.

Bettenhausen, B., M. Hrabe de Angelis, D. Simon, J. L. Guenet and A. Gossler (1995) Transient and restricted expression during mouse embryogenesis of Dll1, a murine gene closely related to Drosophila Delta. Development. 121, 2407-18.

Bibel, M., J. Richter, K. Schrenk, K. L. Tucker, V. Staiger, M. Korte, M. Goetz and Y. A. Barde (2004) Differentiation of mouse embryonic stem cells into a defined neuronal lineage. Nat Neurosci. 7, 1003-9.

Bland, C. E., P. Kimberly and M. D. Rand (2003) Notch-induced proteolysis and nuclear localization of the Delta ligand. J Biol Chem. 278, 13607-10.

Bolos, V., J. Grego-Bessa and J. L. de la Pompa (2007) Notch signaling in development and cancer. Endocr Rev. 28, 339-63.

Brou, C., F. Logeat, N. Gupta, C. Bessia, O. LeBail, J. R. Doedens, A. Cumano, P. Roux, R. A. Black and A. Israel (2000) A novel proteolytic cleavage involved in Notch signaling: the role of the disintegrin-metalloprotease TACE. Mol Cell. 5, 207-16.

Brown, M. S., J. Ye, R. B. Rawson and J. L. Goldstein (2000) Regulated intramembrane proteolysis: a control mechanism conserved from bacteria to humans. Cell. 100, 3918.

Buoso, E., C. Lanni, G. Schettini, S. Govoni and M. Racchi (2011) beta-Amyloid precursor protein metabolism: focus on the functions and degradation of its intracellular domain. Pharmacol Res. 62, 308-17.

Buxbaum, J. D., K. N. Liu, Y. Luo, J. L. Slack, K. L. Stocking, J. J. Peschon, R. S. Johnson, B. J. Castner, D. P. Cerretti and R. A. Black (1998) Evidence that tumor necrosis factor alpha converting enzyme is involved in regulated alpha-secretase cleavage of the Alzheimer amyloid protein precursor. J Biol Chem. 273, 27765-7.

Cao, X. and T. C. Sudhof (2001) A transcriptionally [correction of transcriptively] active complex of APP with Fe65 and histone acetyltransferase Tip60. Science. 293, 115-20.

Chenn, A. (2005) The simple life (of cortical progenitors). Neuron. 45, 817-9.

Cupers, P., I. Orlans, K. Craessaerts, W. Annaert and B. De Strooper (2001) The amyloid precursor protein (APP)-cytoplasmic fragment generated by gamma-secretase is rapidly degraded but distributes partially in a nuclear fraction of neurones in culture. J Neurochem. 78, 1168-78.

Dennler, S., S. Itoh, D. Vivien, P. ten Dijke, S. Huet and J. M. Gauthier (1998) Direct binding of Smad3 and Smad4 to critical TGF beta-inducible elements in the promoter of human plasminogen activator inhibitor-type 1 gene. EMBO J. 17, 3091-100.

Derynck, R. and Y. E. Zhang (2003) Smad-dependent and Smad-independent pathways in TGF-beta family signalling. Nature. $425,577-84$.

Doan, A., G. Thinakaran, D. R. Borchelt, H. H. Slunt, T. Ratovitsky, M. Podlisny, D. J. Selkoe, M. Seeger, S. E. Gandy, D. L. Price and S. S. Sisodia (1996) Protein topology of presenilin 1. Neuron. 17, 1023-30.

Dunwoodie, S. L., D. Henrique, S. M. Harrison and R. S. Beddington (1997) Mouse Dll3: a novel divergent Delta gene which may complement the function of other Delta 
homologues during early pattern formation in the mouse embryo. Development. 124, 3065-76.

Edbauer, D., M. Willem, S. Lammich, H. Steiner and C. Haass (2002) Insulin-degrading enzyme rapidly removes the beta-amyloid precursor protein intracellular domain (AICD). J Biol Chem. 277, 13389-93.

Ellisen, L. W., J. Bird, D. C. West, A. L. Soreng, T. C. Reynolds, S. D. Smith and J. Sklar (1991) TAN-1, the human homolog of the Drosophila notch gene, is broken by chromosomal translocations in T lymphoblastic neoplasms. Cell. 66, 649-61.

Eppert, K., S. W. Scherer, H. Ozcelik, R. Pirone, P. Hoodless, H. Kim, L. C. Tsui, B. Bapat, S. Gallinger, I. L. Andrulis, G. H. Thomsen, J. L. Wrana and L. Attisano (1996) MADR2 maps to 18q21 and encodes a TGFbeta-regulated MAD-related protein that is functionally mutated in colorectal carcinoma. Cell. 86, 543-52.

Esch, F. S., P. S. Keim, E. C. Beattie, R. W. Blacher, A. R. Culwell, T. Oltersdorf, D. McClure and P. J. Ward (1990) Cleavage of amyloid beta peptide during constitutive processing of its precursor. Science. 248, 1122-4.

Farzan, M., C. E. Schnitzler, N. Vasilieva, D. Leung and H. Choe (2000) BACE2, a beta secretase homolog, cleaves at the beta site and within the amyloid-beta region of the amyloid-beta precursor protein. Proc Natl Acad Sci U S A. 97, 9712-7.

Fitzgerald, K. and I. Greenwald (1995) Interchangeability of Caenorhabditis elegans DSL proteins and intrinsic signalling activity of their extracellular domains in vivo. Development. 121, 4275-82.

Fleming, R. J., T. N. Scottgale, R. J. Diederich and S. Artavanis-Tsakonas (1990) The gene Serrate encodes a putative EGF-like transmembrane protein essential for proper ectodermal development in Drosophila melanogaster. Genes Dev. 4, 2188-201.

Fortini, M. E. (2009) Notch signaling: the core pathway and its posttranslational regulation. Dev Cell. 16, 633-47.

Frise, E., J. A. Knoblich, S. Younger-Shepherd, L. Y. Jan and Y. N. Jan (1996) The Drosophila Numb protein inhibits signaling of the Notch receptor during cell-cell interaction in sensory organ lineage. Proc Natl Acad Sci U S A. 93, 11925-32.

Gao, Y. and S. W. Pimplikar (2001) The gamma -secretase-cleaved C-terminal fragment of amyloid precursor protein mediates signaling to the nucleus. Proc Natl Acad Sci U S A. 98, 14979-84.

Ghosal, K., D. L. Vogt, M. Liang, Y. Shen, B. T. Lamb and S. W. Pimplikar (2009) Alzheimer's disease-like pathological features in transgenic mice expressing the APP intracellular domain. Proc Natl Acad Sci U S A. 106, 18367-72.

Guenette, S. Y. (2002) A role for APP in motility and transcription? Trends Pharmacol Sci. 23, 203-5; discussion 205-6.

Guo, M., L. Y. Jan and Y. N. Jan (1996) Control of daughter cell fates during asymmetric division: interaction of Numb and Notch. Neuron. 17, 27-41.

Gupta-Rossi, N., E. Six, O. LeBail, F. Logeat, P. Chastagner, A. Olry, A. Israel and C. Brou (2004) Monoubiquitination and endocytosis direct gamma-secretase cleavage of activated Notch receptor. J Cell Biol. 166, 73-83.

Haass, C. and D. J. Selkoe (1993) Cellular processing of beta-amyloid precursor protein and the genesis of amyloid beta-peptide. Cell. 75, 1039-42.

Hardy, J. (1997) Amyloid, the presenilins and Alzheimer's disease. Trends Neurosci. 20, 154-9. 
Hardy, J. and D. J. Selkoe (2002) The amyloid hypothesis of Alzheimer's disease: progress and problems on the road to therapeutics. Science. 297, 353-6.

Henderson, S. T., D. Gao, E. J. Lambie and J. Kimble (1994) lag-2 may encode a signaling ligand for the GLP-1 and LIN-12 receptors of C. elegans. Development. 120, 2913-24.

Henderson, S. T., D. Gao, S. Christensen and J. Kimble (1997) Functional domains of LAG-2, a putative signaling ligand for LIN-12 and GLP-1 receptors in Caenorhabditis elegans. Mol Biol Cell. 8, 1751-62.

Hiratochi, M., H. Nagase, Y. Kuramochi, C. S. Koh, T. Ohkawara and K. Nakayama (2007) The Delta intracellular domain mediates TGF-beta/Activin signaling through binding to Smads and has an important bi-directional function in the Notch-Delta signaling pathway. Nucleic Acids Res. 35, 912-22.

Ho, A. and T. C. Sudhof (2004) Binding of F-spondin to amyloid-beta precursor protein: a candidate amyloid-beta precursor protein ligand that modulates amyloid-beta precursor protein cleavage. Proc Natl Acad Sci U S A. 101, 2548-53.

Hoodless, P. A., T. Haerry, S. Abdollah, M. Stapleton, M. B. O'Connor, L. Attisano and J. L. Wrana (1996) MADR1, a MAD-related protein that functions in BMP2 signaling pathways. Cell. 85, 489-500.

Hung, A. Y., E. H. Koo, C. Haass and D. J. Selkoe (1992) Increased expression of betaamyloid precursor protein during neuronal differentiation is not accompanied by secretory cleavage. Proc Natl Acad Sci U S A. 89, 9439-43.

Ikeuchi, T. and S. S. Sisodia (2003) The Notch ligands, Delta1 and Jagged2, are substrates for presenilin-dependent "gamma-secretase" cleavage. J Biol Chem. 278, 7751-4.

Imayoshi, I. and R. Kageyama (2011) The role of notch signaling in adult neurogenesis. Mol Neurobiol. 44, 7-12.

Iso, T., V. Sartorelli, C. Poizat, S. Iezzi, H. Y. Wu, G. Chung, L. Kedes and Y. Hamamori (2001) HERP, a novel heterodimer partner of HES/E(spl) in Notch signaling. Mol Cell Biol. 21, 6080-9.

Itoh, M., C. H. Kim, G. Palardy, T. Oda, Y. J. Jiang, D. Maust, S. Y. Yeo, K. Lorick, G. J. Wright, L. Ariza-McNaughton, A. M. Weissman, J. Lewis, S. C. Chandrasekharappa and A. B. Chitnis (2003) Mind bomb is a ubiquitin ligase that is essential for efficient activation of Notch signaling by Delta. Dev Cell. 4, 67-82.

Iwatsubo, T. (2004) The gamma-secretase complex: machinery for intramembrane proteolysis. Curr Opin Neurobiol. 14, 379-83.

Jonk, L. J., S. Itoh, C. H. Heldin, P. ten Dijke and W. Kruijer (1998) Identification and functional characterization of a Smad binding element (SBE) in the JunB promoter that acts as a transforming growth factor-beta, activin, and bone morphogenetic protein-inducible enhancer. J Biol Chem. 273, 21145-52.

Joutel, A., C. Corpechot, A. Ducros, K. Vahedi, H. Chabriat, P. Mouton, S. Alamowitch, V. Domenga, M. Cecillion, E. Marechal, J. Maciazek, C. Vayssiere, C. Cruaud, E. A. Cabanis, M. M. Ruchoux, J. Weissenbach, J. F. Bach, M. G. Bousser and E. TournierLasserve (1996) Notch3 mutations in CADASIL, a hereditary adult-onset condition causing stroke and dementia. Nature. 383, 707-10.

Justice, N. J. and Y. N. Jan (2002) Variations on the Notch pathway in neural development. Curr Opin Neurobiol. 12, 64-70.

Kageyama, R., T. Ohtsuka and T. Kobayashi (2007) The Hes gene family: repressors and oscillators that orchestrate embryogenesis. Development. 134, 1243-51. 
Kageyama, R., T. Ohtsuka, H. Shimojo and I. Imayoshi (2008) Dynamic Notch signaling in neural progenitor cells and a revised view of lateral inhibition. Nat Neurosci. 11, 1247-51.

Kang, J., H. G. Lemaire, A. Unterbeck, J. M. Salbaum, C. L. Masters, K. H. Grzeschik, G. Multhaup, K. Beyreuther and B. Muller-Hill (1987) The precursor of Alzheimer's disease amyloid A4 protein resembles a cell-surface receptor. Nature. 325, 733-6.

Kimberly, W. T., J. B. Zheng, S. Y. Guenette and D. J. Selkoe (2001) The intracellular domain of the beta-amyloid precursor protein is stabilized by Fe65 and translocates to the nucleus in a notch-like manner. J Biol Chem. 276, 40288-92.

Kimberly, W. T., J. B. Zheng, T. Town, R. A. Flavell and D. J. Selkoe (2005) Physiological regulation of the beta-amyloid precursor protein signaling domain by c-Jun Nterminal kinase JNK3 during neuronal differentiation. J Neurosci. 25, 5533-43.

Kimble, J. and P. Simpson (1997) The LIN-12/Notch signaling pathway and its regulation. Annu Rev Cell Dev Biol. 13, 333-61.

Koo, E. H. and R. Kopan (2004) Potential role of presenilin-regulated signaling pathways in sporadic neurodegeneration. Nat Med. 10 Suppl, S26-33.

Kopan, R., E. H. Schroeter, H. Weintraub and J. S. Nye (1996) Signal transduction by activated mNotch: importance of proteolytic processing and its regulation by the extracellular domain. Proc Natl Acad Sci U S A. 93, 1683-8.

Kopan, R. and M. X. Ilagan (2004) Gamma-secretase: proteasome of the membrane? Nat Rev Mol Cell Biol. 5, 499-504.

Kopan, R. and M. X. Ilagan (2009) The canonical Notch signaling pathway: unfolding the activation mechanism. Cell. 137, 216-33.

Kopczynski, C. C., A. K. Alton, K. Fechtel, P. J. Kooh and M. A. Muskavitch (1988) Delta, a Drosophila neurogenic gene, is transcriptionally complex and encodes a protein related to blood coagulation factors and epidermal growth factor of vertebrates. Genes Dev. 2, 1723-35.

Kretzschmar, M., F. Liu, A. Hata, J. Doody and J. Massague (1997) The TGF-beta family mediator Smad1 is phosphorylated directly and activated functionally by the BMP receptor kinase. Genes Dev. 11, 984-95.

Lammich, S., E. Kojro, R. Postina, S. Gilbert, R. Pfeiffer, M. Jasionowski, C. Haass and F. Fahrenholz (1999) Constitutive and regulated alpha-secretase cleavage of Alzheimer's amyloid precursor protein by a disintegrin metalloprotease. Proc Natl Acad Sci U S A. 96, 3922-7.

Laping, N. J., E. Grygielko, A. Mathur, S. Butter, J. Bomberger, C. Tweed, W. Martin, J. Fornwald, R. Lehr, J. Harling, L. Gaster, J. F. Callahan and B. A. Olson (2002) Inhibition of transforming growth factor (TGF)-beta1-induced extracellular matrix with a novel inhibitor of the TGF-beta type I receptor kinase activity: SB-431542. Mol Pharmacol. 62, 58-64.

LaVoie, M. J. and D. J. Selkoe (2003) The Notch ligands, Jagged and Delta, are sequentially processed by alpha-secretase and presenilin/gamma-secretase and release signaling fragments. J Biol Chem. 278, 34427-37.

Lee, M. K., H. H. Slunt, L. J. Martin, G. Thinakaran, G. Kim, S. E. Gandy, M. Seeger, E. Koo, D. L. Price and S. S. Sisodia (1996) Expression of presenilin 1 and 2 (PS1 and PS2) in human and murine tissues. J Neurosci. 16, 7513-25. 
Leimeister, C., A. Externbrink, B. Klamt and M. Gessler (1999) Hey genes: a novel subfamily of hairy- and Enhancer of split related genes specifically expressed during mouse embryogenesis. Mech Dev. 85, 173-7.

Levitan, D. and I. Greenwald (1995) Facilitation of lin-12-mediated signalling by sel-12, a Caenorhabditis elegans S182 Alzheimer's disease gene. Nature. 377, 351-4.

Levy-Lahad, E., W. Wasco, P. Poorkaj, D. M. Romano, J. Oshima, W. H. Pettingell, C. E. Yu, P. D. Jondro, S. D. Schmidt, K. Wang and et al. (1995) Candidate gene for the chromosome 1 familial Alzheimer's disease locus. Science. 269, 973-7.

Lewis, J. (1998) Notch signalling and the control of cell fate choices in vertebrates. Semin Cell Dev Biol. 9, 583-9.

Leyssen, M., D. Ayaz, S. S. Hebert, S. Reeve, B. De Strooper and B. A. Hassan (2005) Amyloid precursor protein promotes post-developmental neurite arborization in the Drosophila brain. EMBO J. 24, 2944-55.

Lindsell, C. E., C. J. Shawber, J. Boulter and G. Weinmaster (1995) Jagged: a mammalian ligand that activates Notch1. Cell. 80, 909-17.

Logeat, F., C. Bessia, C. Brou, O. LeBail, S. Jarriault, N. G. Seidah and A. Israel (1998) The Notch1 receptor is cleaved constitutively by a furin-like convertase. Proc Natl Acad Sci U S A. 95, 8108-12.

Lorenzo, A., M. Yuan, Z. Zhang, P. A. Paganetti, C. Sturchler-Pierrat, M. Staufenbiel, J. Mautino, F. S. Vigo, B. Sommer and B. A. Yankner (2000) Amyloid beta interacts with the amyloid precursor protein: a potential toxic mechanism in Alzheimer's disease. Nat Neurosci. 3, 460-4.

Lu, J., Y. Wu, N. Sousa and O. F. Almeida (2005) SMAD pathway mediation of BDNF and TGF beta 2 regulation of proliferation and differentiation of hippocampal granule neurons. Development. 132, 3231-42.

McCarthy, J. V., C. Twomey and P. Wujek (2009) Presenilin-dependent regulated intramembrane proteolysis and gamma-secretase activity. Cell Mol Life Sci. 66, 153455.

McCright, B., J. Lozier and T. Gridley (2002) A mouse model of Alagille syndrome: Notch2 as a genetic modifier of Jag1 haploinsufficiency. Development. 129, 1075-82.

Mello, C. C., B. W. Draper and J. R. Priess (1994) The maternal genes apx-1 and glp-1 and establishment of dorsal-ventral polarity in the early C. elegans embryo. Cell. 77, 95106.

Miyazawa, K., M. Shinozaki, T. Hara, T. Furuya and K. Miyazono (2002) Two major Smad pathways in TGF-beta superfamily signalling. Genes Cells. 7, 1191-204.

Nagase, H., C. S. Koh and K. Nakayama (2011) gamma-Secretase-regulated signaling pathways, such as notch signaling, mediate the differentiation of hematopoietic stem cells, development of the immune system, and peripheral immune responses. Curr Stem Cell Res Ther. 6, 131-41.

Nakao, A., T. Imamura, S. Souchelnytskyi, M. Kawabata, A. Ishisaki, E. Oeda, K. Tamaki, J. Hanai, C. H. Heldin, K. Miyazono and P. ten Dijke (1997) TGF-beta receptormediated signalling through Smad2, Smad3 and Smad4. EMBO J. 16, 5353-62.

Nakayama, K., K. Nagase, Y. Tokutake, C. S. Koh, M. Hiratochi, T. Ohkawara and N. Nakayama (2004) Multiple POU-binding motifs, recognized by tissue-specific nuclear factors, are important for Dll1 gene expression in neural stem cells. Biochem Biophys Res Commun. 325, 991-6. 
Nakayama, K., H. Nagase, M. Hiratochi, C. S. Koh and T. Ohkawara (2008a) Similar mechanisms regulated by gamma-secretase are involved in both directions of the bi-directional Notch-Delta signaling pathway as well as play a potential role in signaling events involving type 1 transmembrane proteins. Curr Stem Cell Res Ther. 3, 288-302.

Nakayama, K., T. Ohkawara, M. Hiratochi, C. S. Koh and H. Nagase (2008b) The intracellular domain of amyloid precursor protein induces neuron-specific apoptosis. Neurosci Lett. 444, 127-31.

Nakayama, K., H. Nagase, C. S. Koh and T. Ohkawara (2011) gamma-Secretase-Regulated Mechanisms Similar to Notch Signaling May Play a Role in Signaling Events, Including APP Signaling, Which Leads to Alzheimer's Disease. Cell Mol Neurobiol. 31, 887-900.

Ni, C. Y., M. P. Murphy, T. E. Golde and G. Carpenter (2001) gamma -Secretase cleavage and nuclear localization of ErbB-4 receptor tyrosine kinase. Science. 294, 2179-81.

Oda, T., A. G. Elkahloun, B. L. Pike, K. Okajima, I. D. Krantz, A. Genin, D. A. Piccoli, P. S. Meltzer, N. B. Spinner, F. S. Collins and S. C. Chandrasekharappa (1997) Mutations in the human Jagged1 gene are responsible for Alagille syndrome. Nat Genet. 16, 235-42.

Ohkawara, T., H. Nagase, C. S. Koh and K. Nakayama (2011) The amyloid precursor protein intracellular domain alters gene expression and induces neuron-specific apoptosis. Gene. 475, 1-9.

Okochi, M., H. Steiner, A. Fukumori, H. Tanii, T. Tomita, T. Tanaka, T. Iwatsubo, T. Kudo, M. Takeda and C. Haass (2002) Presenilins mediate a dual intramembranous gamma-secretase cleavage of Notch-1. EMBO J. 21, 5408-16.

Pan, D. and G. M. Rubin (1997) Kuzbanian controls proteolytic processing of Notch and mediates lateral inhibition during Drosophila and vertebrate neurogenesis. Cell. 90, 271-80.

Park, J. H., D. A. Gimbel, T. GrandPre, J. K. Lee, J. E. Kim, W. Li, D. H. Lee and S. M. Strittmatter (2006) Alzheimer precursor protein interaction with the Nogo-66 receptor reduces amyloid-beta plaque deposition. J Neurosci. 26, 1386-95.

Pierfelice, T., L. Alberi and N. Gaiano (2011) Notch in the vertebrate nervous system: an old dog with new tricks. Neuron. 69, 840-55.

Qi, H., M. D. Rand, X. Wu, N. Sestan, W. Wang, P. Rakic, T. Xu and S. Artavanis-Tsakonas (1999) Processing of the notch ligand delta by the metalloprotease Kuzbanian. Science. 283, 91-4.

Rebay, I., R. J. Fleming, R. G. Fehon, L. Cherbas, P. Cherbas and S. Artavanis-Tsakonas (1991) Specific EGF repeats of Notch mediate interactions with Delta and Serrate: implications for Notch as a multifunctional receptor. Cell. 67, 687-99.

Roehl, H., M. Bosenberg, R. Blelloch and J. Kimble (1996) Roles of the RAM and ANK domains in signaling by the C. elegans GLP-1 receptor. EMBO J. 15, 7002-12.

Rogaev, E. I., R. Sherrington, E. A. Rogaeva, G. Levesque, M. Ikeda, Y. Liang, H. Chi, C. Lin, K. Holman, T. Tsuda and et al. (1995) Familial Alzheimer's disease in kindreds with missense mutations in a gene on chromosome 1 related to the Alzheimer's disease type 3 gene. Nature. 376, 775-8.

Rohn, J. L., A. S. Lauring, M. L. Linenberger and J. Overbaugh (1996) Transduction of Notch2 in feline leukemia virus-induced thymic lymphoma. J Virol. 70, 8071-80. 
Ryan, K. A. and S. W. Pimplikar (2005) Activation of GSK-3 and phosphorylation of CRMP2 in transgenic mice expressing APP intracellular domain. J Cell Biol. 171, 327-35.

Sarkar, N. H., S. Haga, A. F. Lehner, W. Zhao, S. Imai and K. Moriwaki (1994) Insertional mutation of int protooncogenes in the mammary tumors of a new strain of mice derived from the wild in China: normal- and tumor-tissue-specific expression of int-3 transcripts. Virology. 203, 52-62.

Schnabel, J. (2009) Alzheimer's theory makes a splash. Nature. 459, 310.

Schroeter, E. H., J. A. Kisslinger and R. Kopan (1998) Notch-1 signalling requires ligandinduced proteolytic release of intracellular domain. Nature. 393, 382-6.

Schulz, J. G., W. Annaert, J. Vandekerckhove, P. Zimmermann, B. De Strooper and G. David (2003) Syndecan 3 intramembrane proteolysis is presenilin/gamma-secretasedependent and modulates cytosolic signaling. J Biol Chem. 278, 48651-7.

Selkoe, D. J. (2001) Alzheimer's disease: genes, proteins, and therapy. Physiol Rev. 81, 741-66.

Selkoe, D. and R. Kopan (2003) Notch and Presenilin: regulated intramembrane proteolysis links development and degeneration. Annu Rev Neurosci. 26, 565-97.

Selkoe, D. J. and M. S. Wolfe (2007) Presenilin: running with scissors in the membrane. Cell. 131, 215-21.

Shah, S., S. F. Lee, K. Tabuchi, Y. H. Hao, C. Yu, Q. LaPlant, H. Ball, C. E. Dann, 3rd, T. Sudhof and G. Yu (2005) Nicastrin functions as a gamma-secretase-substrate receptor. Cell. 122, 435-47.

Shawber, C., J. Boulter, C. E. Lindsell and G. Weinmaster (1996) Jagged2: a serrate-like gene expressed during rat embryogenesis. Dev Biol. 180, 370-6.

Sherrington, R., E. I. Rogaev, Y. Liang, E. A. Rogaeva, G. Levesque, M. Ikeda, H. Chi, C. Lin, G. Li, K. Holman, T. Tsuda, L. Mar, J. F. Foncin, A. C. Bruni, M. P. Montesi, S. Sorbi, I. Rainero, L. Pinessi, L. Nee, I. Chumakov, D. Pollen, A. Brookes, P. Sanseau, R. J. Polinsky, W. Wasco, H. A. Da Silva, J. L. Haines, M. A. Perkicak-Vance, R. E. Tanzi, A. D. Roses, P. E. Fraser, J. M. Rommens and P. H. St George-Hyslop (1995) Cloning of a gene bearing missense mutations in early-onset familial Alzheimer's disease. Nature. 375, 754-60.

Shimojo, H., T. Ohtsuka and R. Kageyama (2011) Dynamic expression of notch signaling genes in neural stem/ progenitor cells. Front Neurosci. 5, 78-84.

Shutter, J. R., S. Scully, W. Fan, W. G. Richards, J. Kitajewski, G. A. Deblandre, C. R. Kintner and K. L. Stark (2000) Dll4, a novel Notch ligand expressed in arterial endothelium. Genes Dev. 14, 1313-8.

Sisodia, S. S., E. H. Koo, P. N. Hoffman, G. Perry and D. L. Price (1993) Identification and transport of full-length amyloid precursor proteins in rat peripheral nervous system. J Neurosci. 13, 3136-42.

Six, E., D. Ndiaye, Y. Laabi, C. Brou, N. Gupta-Rossi, A. Israel and F. Logeat (2003) The Notch ligand Delta1 is sequentially cleaved by an ADAM protease and gammasecretase. Proc Natl Acad Sci U S A. 100, 7638-43.

Soba, P., S. Eggert, K. Wagner, H. Zentgraf, K. Siehl, S. Kreger, A. Lower, A. Langer, G. Merdes, R. Paro, C. L. Masters, U. Muller, S. Kins and K. Beyreuther (2005) Homoand heterodimerization of APP family members promotes intercellular adhesion. EMBO J. 24, 3624-34.

Spana, E. P. and C. Q. Doe (1996) Numb antagonizes Notch signaling to specify sibling neuron cell fates. Neuron. 17, 21-6. 
Sparrow, D. B., M. Clements, S. L. Withington, A. N. Scott, J. Novotny, D. Sillence, K. Kusumi, R. S. Beddington and S. L. Dunwoodie (2002) Diverse requirements for Notch signalling in mammals. Int J Dev Biol. 46, 365-74.

Struhl, G. and A. Adachi (2000) Requirements for presenilin-dependent cleavage of notch and other transmembrane proteins. Mol Cell. 6, 625-36.

Suzuki, A., C. Chang, J. M. Yingling, X. F. Wang and A. Hemmati-Brivanlou (1997) Smad5 induces ventral fates in Xenopus embryo. Dev Biol. 184, 402-5.

Tax, F. E., J. J. Yeargers and J. H. Thomas (1994) Sequence of C. elegans lag-2 reveals a cellsignalling domain shared with Delta and Serrate of Drosophila. Nature. 368, 150-4.

Terry RD, K. R., Bick KL, Sisodia SS (1999) Alzheimer's disease., Lippincott, Williams \& Wilkins, Philadelphia

Thinakaran, G., D. R. Borchelt, M. K. Lee, H. H. Slunt, L. Spitzer, G. Kim, T. Ratovitsky, F. Davenport, C. Nordstedt, M. Seeger, J. Hardy, A. I. Levey, S. E. Gandy, N. A. Jenkins, N. G. Copeland, D. L. Price and S. S. Sisodia (1996) Endoproteolysis of presenilin 1 and accumulation of processed derivatives in vivo. Neuron. 17, 181-90.

Vassar, R., B. D. Bennett, S. Babu-Khan, S. Kahn, E. A. Mendiaz, P. Denis, D. B. Teplow, S. Ross, P. Amarante, R. Loeloff, Y. Luo, S. Fisher, J. Fuller, S. Edenson, J. Lile, M. A. Jarosinski, A. L. Biere, E. Curran, T. Burgess, J. C. Louis, F. Collins, J. Treanor, G. Rogers and M. Citron (1999) Beta-secretase cleavage of Alzheimer's amyloid precursor protein by the transmembrane aspartic protease BACE. Science. 286, 735-41.

Vazquez, M. C., L. M. Vargas, N. C. Inestrosa and A. R. Alvarez (2009) c-Abl modulates AICD dependent cellular responses: transcriptional induction and apoptosis. J Cell Physiol. 220, 136-43.

Wallberg, A. E., K. Pedersen, U. Lendahl and R. G. Roeder (2002) p300 and PCAF act cooperatively to mediate transcriptional activation from chromatin templates by notch intracellular domains in vitro. Mol Cell Biol. 22, 7812-9.

Wang, Y. and Y. Ha (2004) The X-ray structure of an antiparallel dimer of the human amyloid precursor protein E2 domain. Mol Cell. 15, 343-53.

Wharton, K. A., K. M. Johansen, T. Xu and S. Artavanis-Tsakonas (1985) Nucleotide sequence from the neurogenic locus notch implies a gene product that shares homology with proteins containing EGF-like repeats. Cell. 43, 567-81.

Wu, L., J. C. Aster, S. C. Blacklow, R. Lake, S. Artavanis-Tsakonas and J. D. Griffin (2000) MAML1, a human homologue of Drosophila mastermind, is a transcriptional coactivator for NOTCH receptors. Nat Genet. 26, 484-9.

Yochem, J. and I. Greenwald (1989) glp-1 and lin-12, genes implicated in distinct cell-cell interactions in C. elegans, encode similar transmembrane proteins. Cell. 58, 553-63.

Yoshikai, S., H. Sasaki, K. Doh-ura, H. Furuya and Y. Sakaki (1990) Genomic organization of the human amyloid beta-protein precursor gene. Gene. 87, 257-63.

Yu, G., M. Nishimura, S. Arawaka, D. Levitan, L. Zhang, A. Tandon, Y. Q. Song, E. Rogaeva, F. Chen, T. Kawarai, A. Supala, L. Levesque, H. Yu, D. S. Yang, E. Holmes, P. Milman, Y. Liang, D. M. Zhang, D. H. Xu, C. Sato, E. Rogaev, M. Smith, C. Janus, Y. Zhang, R. Aebersold, L. S. Farrer, S. Sorbi, A. Bruni, P. Fraser and P. St GeorgeHyslop (2000) Nicastrin modulates presenilin-mediated notch/glp-1 signal transduction and betaAPP processing. Nature. 407, 48-54.

Zhang, Y., X. Feng, R. We and R. Derynck (1996) Receptor-associated Mad homologues synergize as effectors of the TGF-beta response. Nature. 383, 168-72. 
Zheng, H. and E. H. Koo (2006) The amyloid precursor protein: beyond amyloid. Mol Neurodegener. 1, 5.

Zhong, W., J. N. Feder, M. M. Jiang, L. Y. Jan and Y. N. Jan (1996) Asymmetric localization of a mammalian numb homolog during mouse cortical neurogenesis. Neuron. 17, 43-53.

Zhong, W., M. M. Jiang, G. Weinmaster, L. Y. Jan and Y. N. Jan (1997) Differential expression of mammalian Numb, Numblike and Notch1 suggests distinct roles during mouse cortical neurogenesis. Development. 124, 1887-97. 


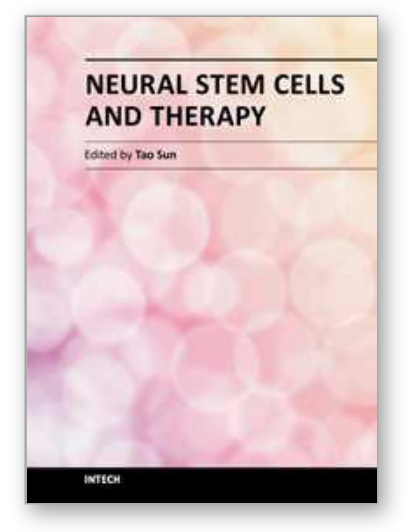

\author{
Neural Stem Cells and Therapy \\ Edited by Dr. Tao Sun
}

ISBN 978-953-307-958-5

Hard cover, 440 pages

Publisher InTech

Published online 15, February, 2012

Published in print edition February, 2012

This book is a collective work of international experts in the neural stem cell field. The book incorporates the characterization of embryonic and adult neural stem cells in both invertebrates and vertebrates. It highlights the history and the most advanced discoveries in neural stem cells, and summarizes the mechanisms of neural stem cell development. In particular, this book provides strategies and discusses the challenges of utilizing neural stem cells for therapy of neurological disorders and brain and spinal cord injuries. It is suitable for general readers, students, doctors and researchers who are interested in understanding the principles of and new discoveries in neural stem cells and therapy.

\title{
How to reference
}

In order to correctly reference this scholarly work, feel free to copy and paste the following:

Kohzo Nakayama, Hisashi Nagase, Chang-Sung Koh and Takeshi Ohkawara (2012). -Secretase-Regulated Signaling Mechanisms: Notch and Amyloid Precursor Protein, Neural Stem Cells and Therapy, Dr. Tao Sun (Ed.), ISBN: 978-953-307-958-5, InTech, Available from: http://www.intechopen.com/books/neural-stem-cellsand-therapy/-secretase-regulated-signaling-mechanisms-notch-and-amyloid-precursor-protein

\section{INTECH}

open science | open minds

\section{InTech Europe}

University Campus STeP Ri Slavka Krautzeka 83/A 51000 Rijeka, Croatia Phone: +385 (51) 770447 Fax: +385 (51) 686166 www.intechopen.com

\section{InTech China}

Unit 405, Office Block, Hotel Equatorial Shanghai No.65, Yan An Road (West), Shanghai, 200040, China 中国上海市延安西路65号上海国际贵都大饭店办公楼 405 单元 Phone: +86-21-62489820

Fax: $+86-21-62489821$ 
(C) 2012 The Author(s). Licensee IntechOpen. This is an open access article distributed under the terms of the Creative Commons Attribution 3.0 License, which permits unrestricted use, distribution, and reproduction in any medium, provided the original work is properly cited. 